\title{
ISO 50001: 2018 and Its Application in a Comprehensive Management System with an Energy-Performance Focus
}

\author{
P. Pablo Poveda-Orjuela ${ }^{1, *}$, J. Carlos García-Díaz ${ }^{2}$, Alexander Pulido-Rojano ${ }^{3}$ (i) \\ and Germán Cañón-Zabala ${ }^{4}$ \\ 1 ASTEQ Technology, 53 Street No. 53-15, Barranquilla 080020, Colombia \\ 2 Centre for Quality and Change Management, Universitat Politècnica de València, Camino de Vera, s/n, \\ 46022 Valencia, Spain; juagardi@eio.upv.es \\ 3 Industrial Engineering Department, Universidad Simón Bolívar, Av. 59 No. 59-92, Barranquilla 080020, \\ Colombia; apulido3@unisimonbolivar.edu.co \\ 4 QUARA Group, 157 Street No. 13B-20, Bogotá 110121, Colombia; gcanonz@quaragroup.com \\ * Correspondence: pedpoor@doctor.upv.es; Tel.: +57-3008897111
}

Received: 24 October 2019; Accepted: 6 December 2019; Published: 10 December 2019

\begin{abstract}
Business progress and human development are linked to the efficient management of energy resources. The research in this paper contributes to the generalized application of good practices that reduce the vulnerability of companies. The research focuses on energy efficiency through comprehensive management systems (CMS), and "thought based on risks and opportunities", considering the discussion about the revision of ISO 50001:2018, the basic approach of the model and the route to implement CMS for quality, safety and health in the workplace, environmental management, energy efficiency, and other risk components. This implementation route, with the acronym CMS QHSE3+, places special emphasis on the functions of strategic planning, operational and risk management, and controls, as well as on deliverables and references to examples, templates, standards, and documents, to facilitate its application general in small and medium enterprises and in the management of energy efficiency.
\end{abstract}

Keywords: comprehensive management system; risk; vulnerability; route; implementation project; energy management; ISO 50001

\section{Introduction}

In line with international standards on management systems, ISO 50001 Energy Management Systems (EnMS) stipulates certain energy saving and efficiency requirements that companies must meet. The ISO/TC 301 Technical Standardization Committee, Energy Management and Energy Saving, reviewed this standard and published it in 2018 [1-3], at the request and requirement of the United Nations Industrial Development Organization (UNIDO), the International Partnership for Energy Efficiency Cooperation (IPEEC), and the Clean Energy Ministerial (CEM) [4,5].

The ISO 9001:2015, ISO 45001:2018, and ISO 14001:2015 standards, together with ISO 50001:2018, have special relevance for organizations around the world, because they bring together the good management practices required by manufacturing, business, and service institutions to meet the requirements of interested parties, prevent risks, and have a strategic approach towards the integral generation of value, energy efficiency, and sustainable success.

For this reason, institutions must promote and guarantee energy efficiency and cost-effective management internally and/or with their stakeholders. Both energy resources and their efficient management are increasingly weighted in the ethical field, in the rational balance among costs, expenses, 
and commercial vulnerability (which is crucial for sustainability), and in the management of risks and opportunities $(\mathrm{R} / \mathrm{O})$.

The problem of survival of companies, and specifically SMEs, is known, which in more than $80 \%$ of cases go bankrupt before reaching five years of creation, due to profitability problems caused by failures in terms of professionalization for planning and management. It is also evident that the failure rate in the management systems implementation projects can reach more than $60 \%$ in the countries with the greatest vulnerability [6-11].

Given this circumstance, it is very important to develop research actions and make available to the business sector, tools to promote and facilitate the widespread application of the good practices of the aforementioned international standards. In this way, entrepreneurial efforts are supported and the sustainable success of SMEs is promoted as the world's business muscle. For this purpose, it is necessary to apply a holistic approach that ensures alignment among strategic management, business management, and process planning and operation, with a comprehensive perspective of risks, opportunities, and energy efficiency.

This is precisely the essence of a system in which management is the one that has an integral and holistic nature. Regardless of the process, the management is aligned in an integral way with the strategic purposes, with the principles and with the way to address the risks and opportunities of strategic, quality, health and safety, environmental, energy efficiency type, or any other component that may affect the purposes of the business, the processes, or the integrity of the resources. The difference is made here, with respect to the commonly used term "integrated management system", where the system is basically the sum or combination of the components. For this reason, throughout this paper, reference is made to a conceptual model and a comprehensive management system (CMS), and not to an integrated management system.

With this approach, this paper has the following objectives:

(1) To construct an inventory of the main aspects not included in the ISO 50001 review, and the critical needs of organizations implementing comprehensive management systems (CMS) QHSE3+, where $Q$ and HS denote quality (ISO 9001) and health and safety at work (ISO 45001), respectively, and E3+ encompasses environmental management (E1, ISO 1400), energy efficiency (E2, ISO 50001), and other applicable risks (+sign). The details are presented in Section 2.1.

(2) To present the model, the route and the key planning tools for implementing a CMS with $\mathrm{R} / \mathrm{O}$, particularly emphasizing the aspects related to the deliverables of QHSE3+ and the QHSE3+ deliverables related to energy efficiency, are described. See Sections 2.2-2.5 and 3.

Several studies have highlighted the need for a simplified and rational merger of integral and risk management, accounting for the applicable references in QHSE3+, or others as determined by the business and its target markets [12-18].

The remainder of this paper is organized as follows: Section 2, with the title Materials and Methods, brings together the different inputs for research, which correspond to: Section 2.1, which presents the structural approach of ISO 50001: 2018, listing the aspects that could be included in future reviews or considered in the guidelines of other members of the ISO 50000 family; Section 2.2, with the application of "thought based on risks and opportunities" in management systems; Section 2.3 that presents the CMS Model QHSE3+, as an application of the systemic design; Section 2.4 that presents the application of the project approach of the QHSE3+ CMS implementation process; and Section 2.5 presenting the general approach of the stages of the QHSE3+ CMS implementation process.

In Section 3 the results obtained in the investigation are presented, analyzed, and discussed, considering the following blocks: Section 3.1 presents the result of applying the methodology of the logical framework of projects, in the definition of problem trees and objectives of the project. Section 3.2 presents the fundamental tool for project planning and management, which results from the creation of a new type of "work breakdown structure", which integrates the CMS QHSE3+ implementation route and project deliverables. Section 3.3 presents the role of energy efficiency in project financial leverage, highlighting the key products of the energy efficiency component, measurement of vulnerability 
reduction, and CMS leverage. Section 3.4 presents the general achievements and benefits obtained during the CMS implementation projects, developed with the model and approach presented here. Section 3.5 contains the discussion on the results obtained in terms of energy efficiency.

Section 4 closes the document with the conclusions, and Annexes A are added, which include the complementary information: A1: The logical structure of the family of standards in force and in development ISO 50000. A2: The general illustration of the application of the model and the route of implementation. A3: the list of acronyms used in the paper.

\section{Material and Methods}

\subsection{Revision of ISO 50001: 2018}

The high-level hierarchical structure, established in Annex SL of ISO/IEC Directives (2018), insists that all standards concerning management systems have 10 chapters with a homologous architecture $[3,19,20]$. Figure 1 shows the hierarchical structure of ISO 50001, which correlates the aspects relevant to the review process based on the plan-do-check-act (PDCA) cycle. The blocks in this figure correspond to Section 2.1.1, Section 2.1.2, Section 2.1.3, Section 2.1.4, Section 2.1.5, Section 2.1.6 of this paper. Section 2.1.7 highlights the key issues that should be considered in future revisions or documents of the ISO 50000 family.

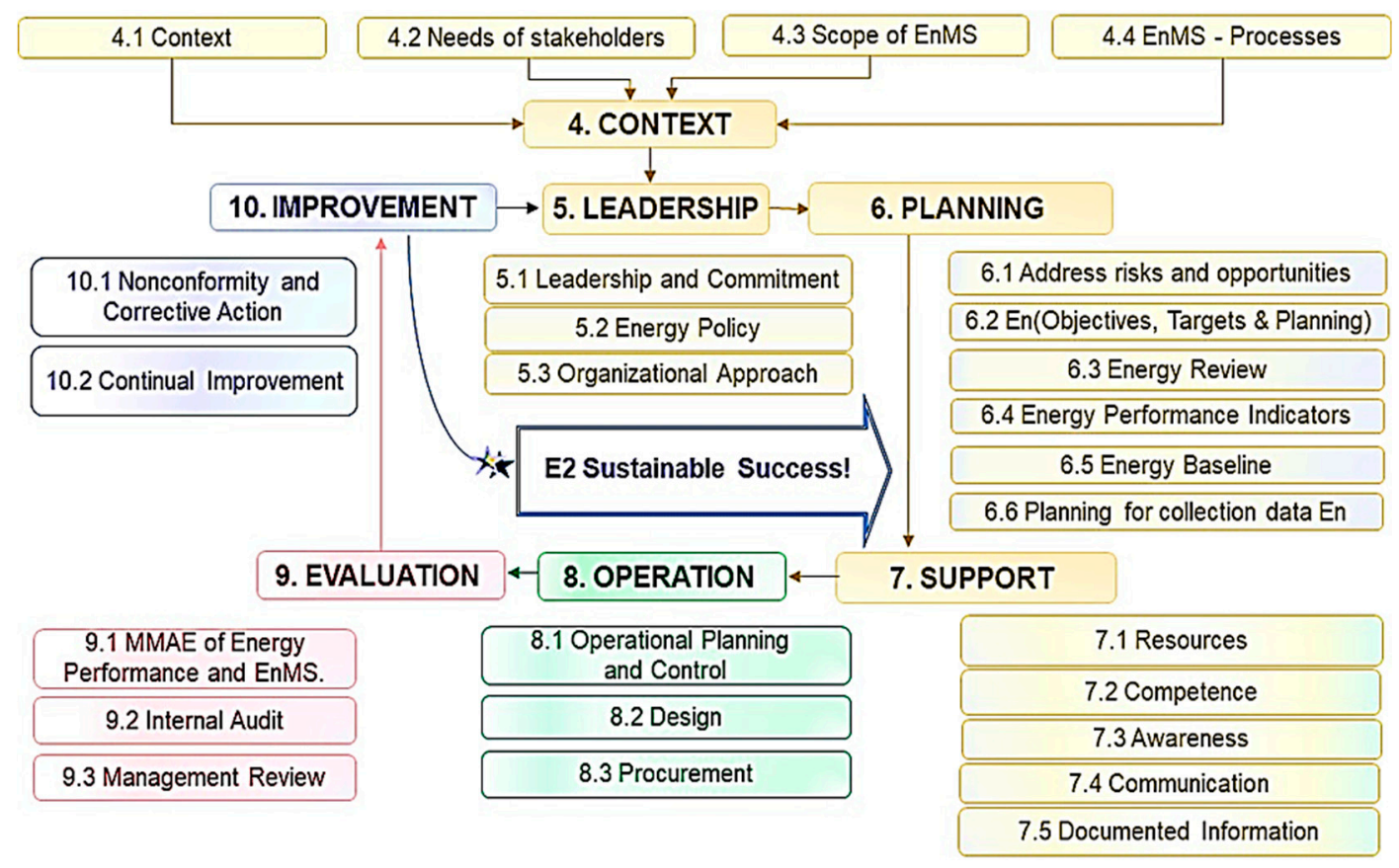

Figure 1. Structural approach of ISO 50001:2018 based on the Deming plan-do-check-act cycle.

\subsubsection{Regarding the Initial Chapters}

The ISO 50001:2011 retains the preliminary sections of "Scope", "Reference Standards", and "Definitions", which cover five blocks of topics: "Aspects Organizational", "Management Systems", "Requirements", "Performance", and "Energy". The terms related to "Energy Review", "Energy Performance", "Performance Indicators", "Energy Baseline", "Monitoring, Measurement, Analysis, and Evaluation (MMAE)", are clarified and specified.

\subsubsection{Requirements Related to "Planning Management" ("P" Chapters of the PDCA Cycle)}

The chapters associated with "Context", "Leadership", "Planning" and "Support" are assigned to parts 4, 5, 6, and 7, of the standard, respectively. These chapters, which constitute the "P" chapters 
of the PDCA cycle in Figure 1, maintain the flow logic in the business domain and its environment, direction, commitment to leadership, and the allocation of resources.

ISO 50001:2011 has a new topic that encompasses the knowledge and understanding of context, focusing on the interest groups related to energy management. This topic analyzes the operational risks/opportunities $(\mathrm{R} / \mathrm{O})$, strengths, and potential internal and external problems of the energy management.

This standard emphasizes the decision-making participation of top management during the cyclic planning, action, feedback, and adjustment activities. The first three of these activities constitute the MMAE management. The R/O concerns, which initiate the planning and formulation of goals, are approached from a context-management perspective. Management planning priorities are determining the energy baseline in conjunction with the key performance indicators (KPI) for energy, the planning and management of $\mathrm{R} / \mathrm{O}$, and the activities highlighted in the energy review. The planning includes the collection of data on energy management, e.g., energy characterization, load censuses, energy diagrams, diagrams of energy consumption versus operations and production over time, and others $[20,21]$.

Requirements related to communication of energy performance and Energy Management System (EnMS) improvements among stakeholders are also established.

\subsubsection{Requirements of Chapter 8 (Management of the "Making" or "To Do" Part of the PDCA Cycle)}

Although Sections 8.1-8.3 of "Operational Control, Design, and Purchasing" are not significantly changed from those in the previous version (ISO 50001:2011), the standard allows implicit emphasis on $\mathrm{R} / \mathrm{O}$ management along three axes:

- Axis of analysis of the process components (workers, materials, methods, machinery, measurement, and environment) versus the risks and controls related to energy efficiency;

- Axis of process design, with particular emphasis on services, sources, uses, generation, distribution, measurement, and control of energy efficiency;

- Axis of energy-efficiency management associated with the purchase of services, equipment, and products. In this form of management, an organization interacts with suppliers, contractors, or allies that develop activities for, or on behalf of, the organization.

\subsubsection{Requirements of Chapter 9 ("Check" (C) Part of the PDCA Cycle)}

Although there are no significant changes from the previous version, the new version emphasizes that MMAE must drive the integral management of R/O toward "understanding, taking decisions and acting with intelligence to achieve sustainable success" [22].

Perhaps for this reason, ISO 50001:2011 is an exemplary standard for management systems, establishing one of the most robust mechanisms for measuring, monitoring, analyzing, and evaluating the energy efficiency and EnMS. On the other hand, specific management and technology developments have improved the definition, implementation, and management of indicators associated with benchmarks and energy performance. These developments include (but are not limited to) reduction of thermal energy, higher efficiency of heating and insulation, higher percentage of thermal saving, economic saving, reduction of carbon emissions, and increase of renewable energies [23-25].

\subsubsection{Requirements of Chapter 10 (Correction, Maintenance, and Improvement Actions of PDCA)}

In ISO 50001:2018, the approach for improving the Energy Management System (EnMS) and energy performance is complemented by improving the three parameters of the management review: "Convenience", "Adequacy", and "Efficiency" of EnMS. This improvement includes:

- The development of energy-saving actions in $\mathrm{R} / \mathrm{O}$ ([26]);

- The analysis of MMAE results and the general performance, which should fulfil the objectives and goals of the EnMS; 
- Analysis of the external and internal factors of the context;

- Output of feedback mechanisms such as audits and the EnMS review;

- The progress and effectiveness of actions related to corrections, responses to incidents and complaints, requirements, breaches, and corrective actions.

This block includes the improvements related to energy planning, along with particular aspects of technological improvements associated with (for example) spatial planning and integrated energy in public, urban, and private spaces, automation, information and communication technologies (ICT), intelligent data analysis, optimization and control methods, and the integration of energy-efficiency management with environmental-management planning.

All measures undertaken must aim to reduce the vulnerability associated with the energy efficiency, which directly involves the operational control component.

When effectively implemented, these measures can be regarded as improvement actions that ratify the good practices contained in the different disclosure documents promoted by the Clean Energy Ministerial, by EMAS in different specific sectors, by the sponsorship of the European Economic Community, and by other entities committed to energy efficiency, pollution prevention, and environmental protection [27-30].

\subsubsection{Changes to Annex A}

The sequence of Annexes A1 to A10 in ISO 50001:2011 is adjusted to suit the new chapters. Specific guidelines are proposed for the approach to energy planning, actions that address the performance-related $\mathrm{R} / \mathrm{O}$, the energy baseline, indicators and the energy review, and the metrological control of the critical measurement equipment associated with the relevant uses and consumption. Annexes A-6 and A-9 also propose specific guidelines for MMAE, auditing, and management review. This feedback management follows a systematic approach based on the information, facts, and statistical analysis of the performance.

\subsubsection{Key Aspects Not Included in ISO 50001:2018}

Figure 2 illustrates the operational logic of the EnMS and the integral management system. The structure of each QHSE3+ component is essentially unchanged from the previous version, but with different particulars of the $\mathrm{R} / \mathrm{O}$ of failure, accidents or diseases, pollution, energy losses, and other relevant factors depending on the nature of the organization.

The topics that should be explicitly considered in future revisions of ISO 50001, or in other standards of the ISO 50000 family, are labeled " $a$ " to " $r$ " in Figure 3. These topics are intended to clarify, reinforce, integrate, or include the following contributions:

a. In the introductory chapters, a structural map of the standards of the ISO 50000 family would reinforce the overview and the fundamental purpose of standard ISO 50001:2018. Another section outlining the principles of integral management and sustainability, similar to the guide contained in ISO 31000: 2018, would also be helpful.

b. The context study should include a strategic and comprehensive analysis that considers the market, business, interest groups, and the geopolitics of energy.

c. The annexes could present the risk management and opportunities of energy efficiency (E2) from an integral and strategic point of view, including the planning and control of product lines, process design, projects, and business approaches.

d. The effective operation of the EnMS demands the coordinated deployment of strategic, tactical and operational levels that align the business culture with sustainable success.

e. A strategic management approach for studying scenarios and trends should be included. This should account for the volatility of the macroeconomic and geopolitical conditions [31]. 
f. The vision that the organization wishes to build must be correlated with the strategy of efficiency and energy saving, and with the organization's survival in the market. This correlation must be explicitly defined and well disseminated.

g. The awareness-related requirements should highlight the importance of the organization's staff understanding the challenges of energy efficiency, knowing their roles in relation to the objectives, and knowing the approach of the programs that support energy management, directly related to their processes.

h. Within the section corresponding to the configuration of plans and programs for energy management, it is necessary to make explicit reference to new technological developments to optimize the integration of the EnMS component with the variable energy demand, and the functionality of the intelligent network in terms of interaction with:

$\bigcirc \quad$ Higher-level energy management platforms, such as support systems for urban energy management decisions [32,33].

$\bigcirc \quad$ Peer-to-peer energy management platforms, such as support systems for district energy management decisions [34-36], and

- Lower-level energy management platforms, such as SCADA subsystems or devices $[37,38]$.

i. The recommendations annex should formulate an integral management policy oriented towards the prevention, compliance, and improvement of the QHSE3+ performance.

j. Chapter 5 would benefit from establishing specific objectives for energy efficiency, which should be aligned with comprehensive policies and strategic objectives.

k. The "Project Management and Development of New Products and Businesses with Perspective of Performance and Energy Saving" approach should be included in the planning and control requirements.

1. In the operational control of energy efficiency (Number 8.1), an integral perspective linked to operational excellence and the control of each process is demanded.

$\mathrm{m}$. The management of organizational development and culture for energy efficiency (E2) needs an explicit reference to ensure the continuity, projections and effectiveness of the EnMS.

n. The function of purchases and supplies should include the requirements of energy performance.

o. The requirements of "knowledge management" and "lessons learned" must be explicitly defined so that the documented information is constituted in the best know-how of the processes.

p. The MMAE approach requires a comprehensive perspective with feedback on the competitive performance of the energy efficiency in product lines, processes, and projects. The planning approach of internal audits should account for the R/O.

q. A section with reference to websites in the annexes, as well as templates, tools and links, such as those found in Forum 27k [39] or IEC 31010: 2009 tools [40], would be helpful. Also, an explicit presentation of the ISO 50004:2014, ISO 50006:2014, and ISO 50015:2014 [41-43] sections that support the interpretation and application of the requirements would encourage good practices, thereby improving the performance, use, and consumption of energy (See Scheme A1 in Appendix A).

r. The text of the standard must clarify the purpose of the EnMS; that is, the creation and protection of value in sustainable competitive success. A key element of this purpose is savings and energy efficiency. 


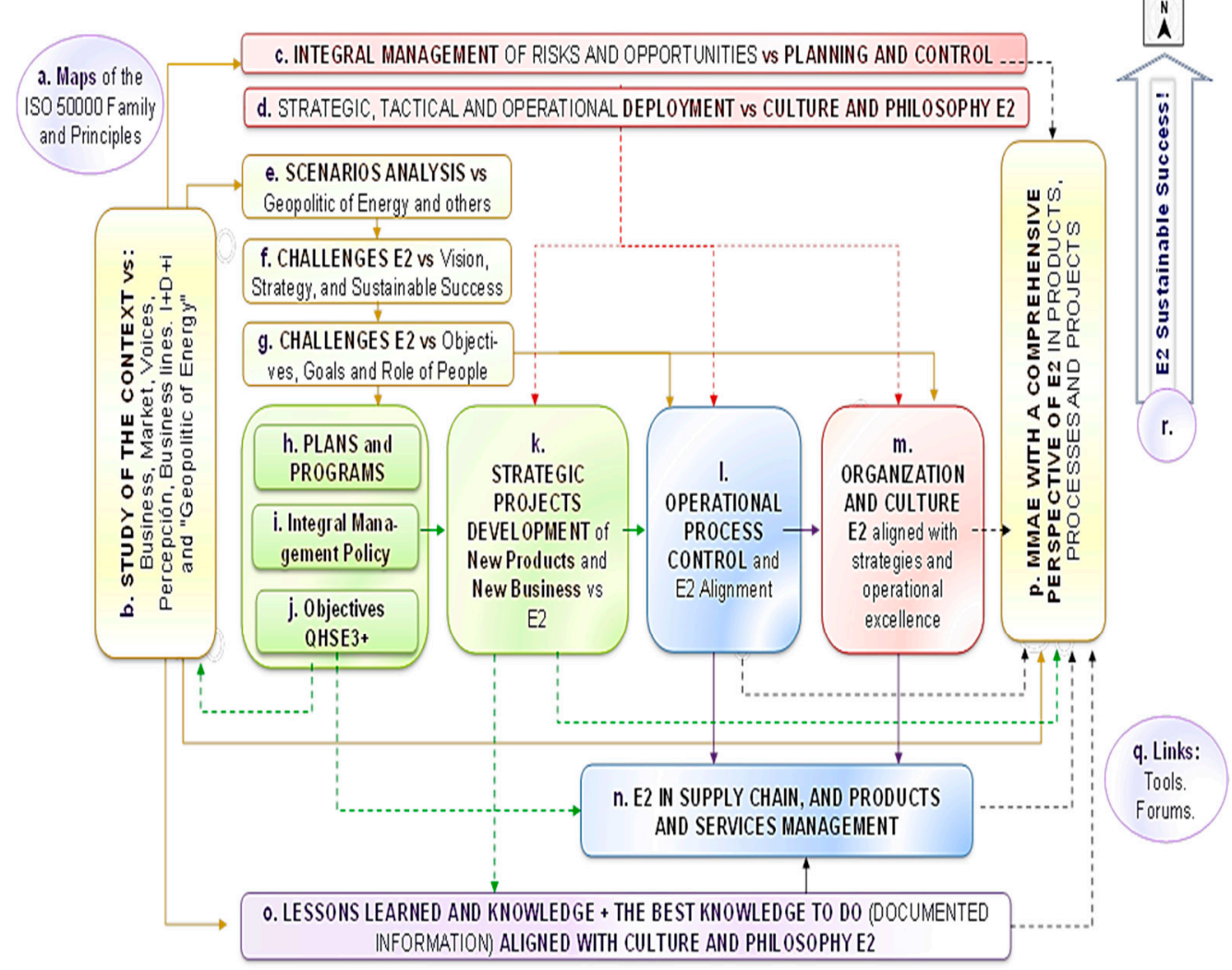

Figure 2. Key topics not included in ISO 50001:2018 (authors' perspective). Source: Developed by the authors based on the requirements and guidelines of ISO 50001:2018.

\section{THE RISKS}

"Effect of uncertainty on objectives. Risk is usually expressed in terms of risk sources, potential events, their consequences,

Establish the Strategic, Organizational and Management Context of..

Identify ... (What can happen and how)

Analyze ... (Possibility x Consequence)

Evaluate ... (Priority List)

Control.Planning and implementing measures

to eliminate, reduce, mitigate, or take

contingency actions on...

Monitoring of the control system and the state of ...

Recording and Reporting. Communication and Consult. Interaction with the parties to have full information about ...

(Identification + Analysis + Evaluation $=$ Risk Assessment $)$ and their likelihood" (ISO 31000:2018).

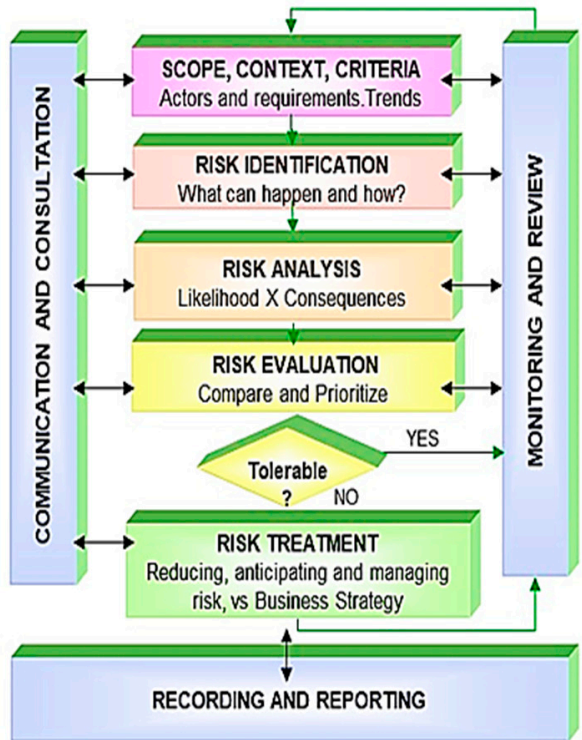

Figure 3. Key aspects of the risk management process. Source: Adapted by the authors from ISO 31000:2018 [22,44]. 


\subsection{Risks and Opportunities-Based Thinking in Management Systems}

The management systems of institutions and companies may be unaware of the ISO standards related to management. A management system should harmoniously integrate processes, people, resources, and methods in a coherent manner, to achieve the fundamental purposes and strategic objectives of sustainable success.

Notwithstanding, ISO standards that establish requirements and recommendations for the components of a management system are justified, because they enable transference of technology, by which good practices can be promoted, disseminated, and demanded in organizations, at both the strategic and operational level of processes and projects. In this way, technology helps to reduce vulnerability and improve the performance of the organization.

Good practices mainly focus on the creation and protection of value, based on planning and control management at the strategic and operational levels of the organization. Good practices that support the ISO norms on management systems are based on risks; in this context, risk management means the anticipation and control of what can and should occur in the processes and business practice. Risk management should strive to meet the strategic objectives, purposes, and commitments associated with the projects, processes, products, and services.

Figure 3 summarizes and correlates the concepts of risk and the risk management process, and the application of risk management at different levels of an organization. Risk management involves strategic decision making on the direction of business and institutions, decisions in planning and project development, decisions in the management of processes, products, and services, and decisions in the interaction of people with their environment and stakeholders [22,44].

The cycle of the risk management process is similar to that of opportunities, and must be implemented on a regular and systematic basis. Depending on its topic, or nature, each risk is managed at different levels (see Figure 4). Especially, each risk requires time to collect and analyze the information, to make decisions, and to plan, execute, feedback, and successfully complete the actions required for the effective management of the risk or opportunity".

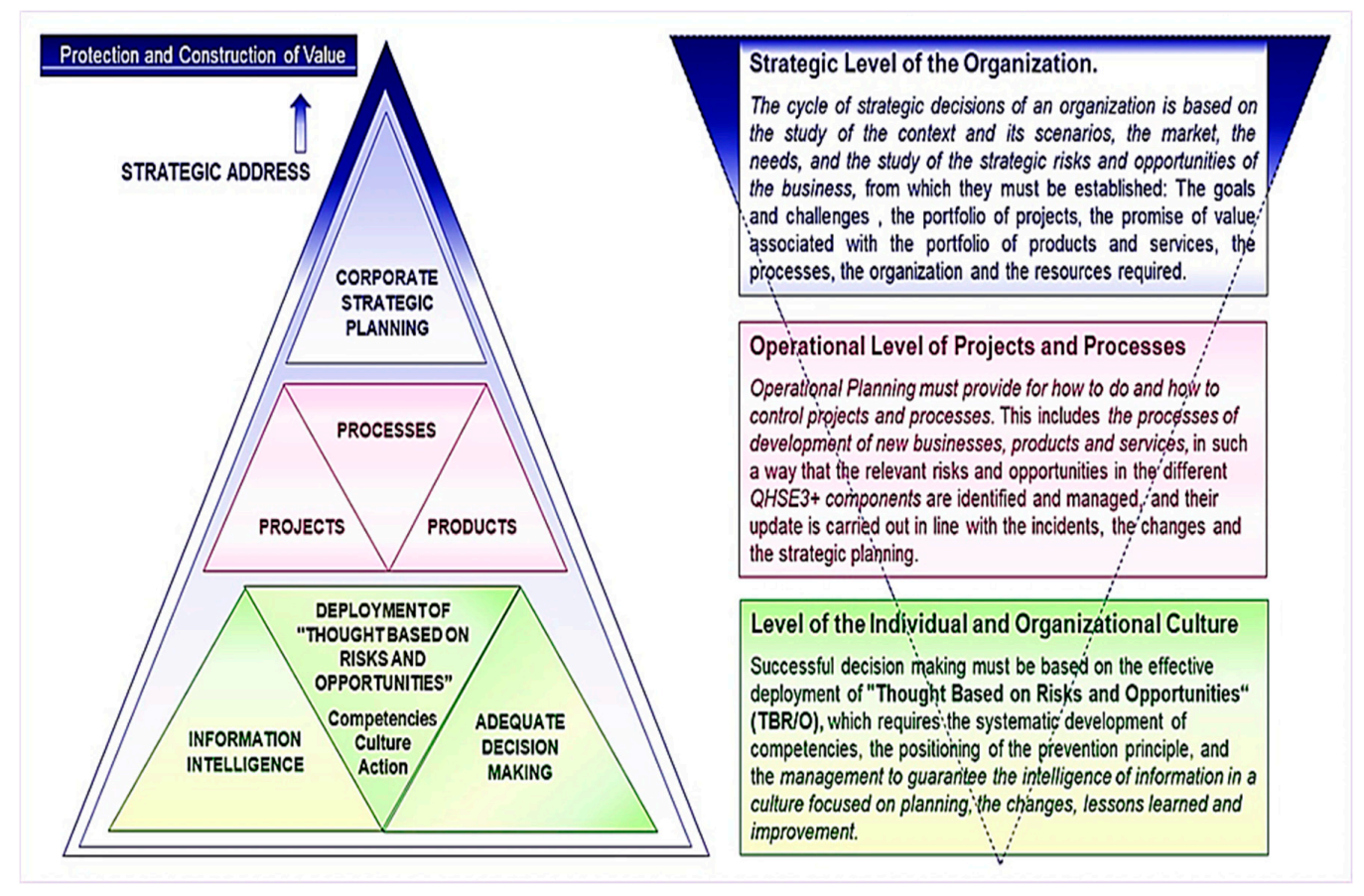

Figure 4. Systematic application of "thought based on risks and opportunities" at different levels of the organization. Source: Adapted by the authors from $[22,40,44]$. 
Whether a decision is made by an operator, a person interacting with a client, a process or project developer, or is the corporate decision of the management team, the successful implementation of "thought based on risks and opportunities", depends on the intelligence of the information, the competences of the decision makers, an integral, inclusive, dynamic and structured approach to management, and consolidation of the principles and values of prevention in the organization. It also requires the leadership, commitment, and direct participation of the steering group [22,44,45].

\subsection{Conceptual Model of CMS QHSE3+: Application of Systemic Design}

Based on general systems theory, conceptual model design and systemic concurrent engineering are applicable to all types of products, services, organisms, and systems [46,47]. Private design schools have integrated graphic design into their functional, ergonomic, and formal components. Exploitation, management, evolution, and mutation objectives of these three components can be developed using the systemic approach.

This strategy was adopted by the Latin Design Network. The Magazine of the International Design Research Network (rdis), the Latin Design Network, has been integrating the work and efforts of design schools and researchers from Argentina, Brazil, Chile, Colombia, Spain, Italy, Mexico, and Venezuela, among others [48-51].

In the present investigation, the conceptual model of the CMS QHSE3+ was configured using the systemic design methodology. The configuration was based on a functional, ergonomic, and shape design. The final graphic result is shown in Figure 5.

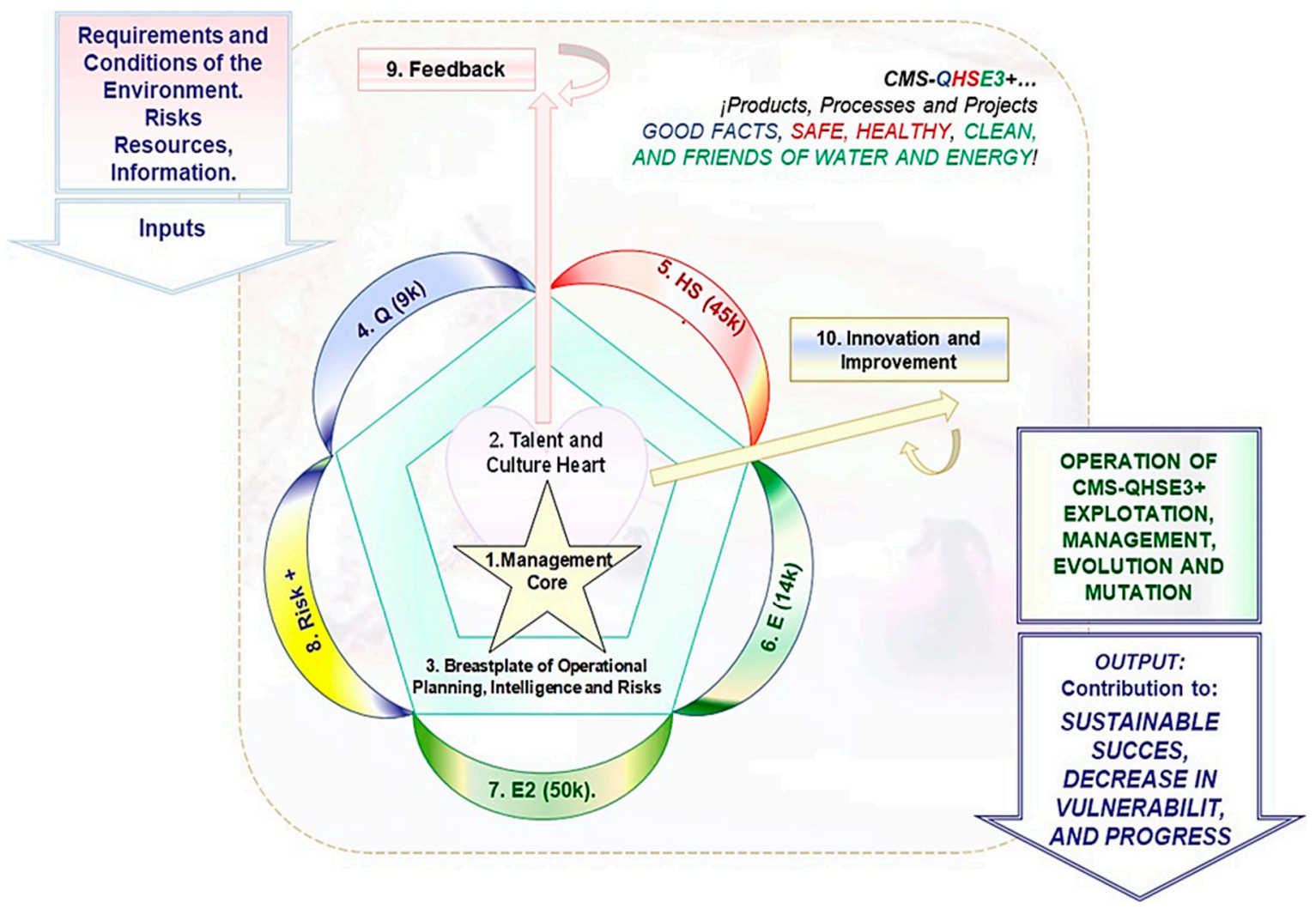

Figure 5. Conceptual model of the comprehensive management systems (CMS) QHSE3+. Source: Adapted by the authors from [52].

Figure 5 shows the ten structural elements composing the configured model [52]. 


\subsubsection{Steering Core}

The steering core is represented by a star representing the direction and strategy of sustainable success. The steering core is integrated and symbiotic with the core business management associated with the development of products and services that characterizes and differentiates organizations.

\subsubsection{Heart of Talent and Culture}

The heart represents the managements of culture, organizational development and knowledge, along with the development of skills, and the strengthening of the social and human sense in the entrepreneurship projects of all organizations seeking sustainable success.

\subsubsection{Intelligence Breastplate, Risk Management, and Operational Planning}

The three-layer breastplate gathers the three fundamental fronts of the CMS: the intelligence of the information and the businesses (first layer), the integral risk management (second layer), and the operational planning (third layer). The third layer is fed by the second layer, and determines the tasks to be completed and what will be controlled in the QHSE3+ components of the different processes.

The model also includes five arms (components D-H) for the QHSE3+ components, as described below. The arms correspond to the application of good practices in operational planning (that is, the QHSE3+ components), considering the high-level structure (HLS) defined by ISO for all management systems standards.

The HLS is based on review processes initiated in 2013, which generated the updated ISO versions ISO 9001:2015, ISO 45001:2018, ISO 14001:2015, and ISO 50001:2018 [53-56].

\subsubsection{Component Q-9k (ISO 9001)}

The $\mathrm{Q}$ component is the blue arm in the model, which corresponds to the operational control of good practices in the quality management of products, services, and processes. The aim is to prevent failures and nonconformities in the design specifications.

\subsubsection{HS Component—45k (ISO 45001)}

The HS component is the red arm in the model, which corresponds to the operational control of good practices in health and safety management. The aim is self-care and the prevention of occupational accidents and diseases.

\subsubsection{Component E-14k (ISO 14001)}

The E1 component is one of two green arms in the model. It corresponds to the operational control of good practices in environmental management. The aim is environmental care and pollution prevention.

\subsubsection{Component E2—50k (ISO 50001)}

The E2 component is the other green arm in the mode, which corresponds to energy efficiency management. The aim is to prevent the non-rational and inefficient use of energy resources.

\subsubsection{Plus Component (+)}

The plus component is the yellow arm in the model, which corresponds to the management of other specific risks that depend on the nature of the organization. For example, some organizations may need to mitigate safety risks, information security risks, smuggling, drug trafficking, or illegal trade. Finally, the model structure includes two axes of dynamics, as described below. 


\subsubsection{Feedback Axis}

The feedback axis covers all components of the system, including aspects related to auditing, indicator management, monitoring, measurement, analysis, and evaluation. It also covers supervision, petitions, complaints, claims, voice management of the special interest groups, and other relevant items.

\subsubsection{Axis of Improvement and Innovation}

The improvement and innovation axis closes the PDCA cycle of the model. Improvement and innovation involves planning, implementing, checking, verifying, receiving feedback, and using the feedback to maintain, correct, prevent, or improve the past performance. Improvement and innovation is integral to the management of all organizations and businesses. The feedback elicits immediate maintenance and corrective actions, and short, medium, and long-term actions of innovation, improvement, and progress.

\subsection{Project Approach Applied to the Implementation of CMS QHSE3+}

The application of good practices in project management is gaining importance daily. Techniques that enable the effective management of the various risks in projects, particularly in projects that implement a CMS with QHSE3+ components, are demanded. Two schools devoted to project management have been consolidated in the past two decades: The PMI Project Management Institute, and the Logical Framework School, which is linked to the World Bank and the Inter-American development Bank (IDB).

However, neither school has submitted proposals that comprehensively unite the strategic and QHSE3+ components [14,15,57-62].

The developments of logical framework/IDB and the PMI Project Management Institute are rarely applied to project planning, launching, development, evaluation, and control in the implementation projects of management systems, or in the corporate projects of SMEs [63-67].

According to the statistics, the certification projects of management systems in SMEs are also unfavorable. For instance, the Standish Group in the Chaos Reports, carried out annually since 1994, reported that failed projects constitute between $17 \%$ and $25 \%$ of the total projects associated with ICT or knowledge management. As a reference value, we suppose that $21 \%$ of management-systems projects in SMEs are unsuccessful. We also consider that the CMS QHSE3+ implementation project is small-to-medium. In the Chaos Reports, the failure statistics of this type of project easily exceed $40 \%[10,68-73]$.

In the Latin American environment, the IDB and its Multilateral Investment Fund, the Chambers of Industry, and the Commerce of Central and South America have gathered the sustainability statistics of clusters ISO 9000 and ISO 14000 projects. The number of SMEs that have successfully completed their certification projects does not exceed $60 \%[11,70,73]$.

Under this premise, different principles and elements of the logical framework project approach were adopted for configuring and implementing the CMS QHSE3+ model. The problem and objectives/deliverables trees were constructed under the project management body of knowledge (PMBOK) guidelines.

The implementation project, task breakdown structure, implementation route, and project plan were also established in PMBOK (examples of the project tree and the breakdown structuring of the implementation path are presented in Section 3).

\subsection{Approach for Developing the CMS QHSE3+ Implementation}

The current trends of the SMEs and projects implementing management systems highlight the importance of supporting entrepreneurs and their SMEs. The provided tools should facilitate and encourage the development of projects applying the good practices contained in the ISO standards $9000,45,000,14,000,50,000$, and others, to each of the QHSE3+ components. 
The authors have participated in the development of a guide for comprehensive risk management and in the configuration of a conceptual model for a CMS QHSE3+, which have been adopted by medium-sized Latin American companies of the manufacturing, pharmaceutical, services sector health, in Family Compensation Funds, and in port logistics operation, among others. (See examples of results in six types of companies in Section 3 and in Schemes 3-5).

The route of implementation of the CMS QHSE3+ model, presented in this paper, emphasizes issues related to the energy efficiency component (E2), in accordance with ISO 50001:2018 [22,45,52].

When designing an implementation route, entrepreneurs must understand the importance of a single management system that supports the achievement of their strategic purposes.

Under the banner of integral management, this system must guarantee that all projects, processes and products of the company adopt the good practices stipulated in international reference standards.

These practices should focus on risk prevention, opportunity exploitation, excellence in operations, and sustainable business success. For this purpose, the company need not certify all components in the QHSE3+ approach, but must cover all the fronts and priorities that generate vulnerability for the organization $[45,52]$.

Figure 6 presents the various stages of the CMS QHSE3+ implementation project. This comprehensive perspective covers any conjugation of standards on management systems, such as complementary approaches to ISO 50004:2014, by integrating the requirements and configuration of the CMS, and prioritizing the strategies deployed through the processes and projects of the organization.

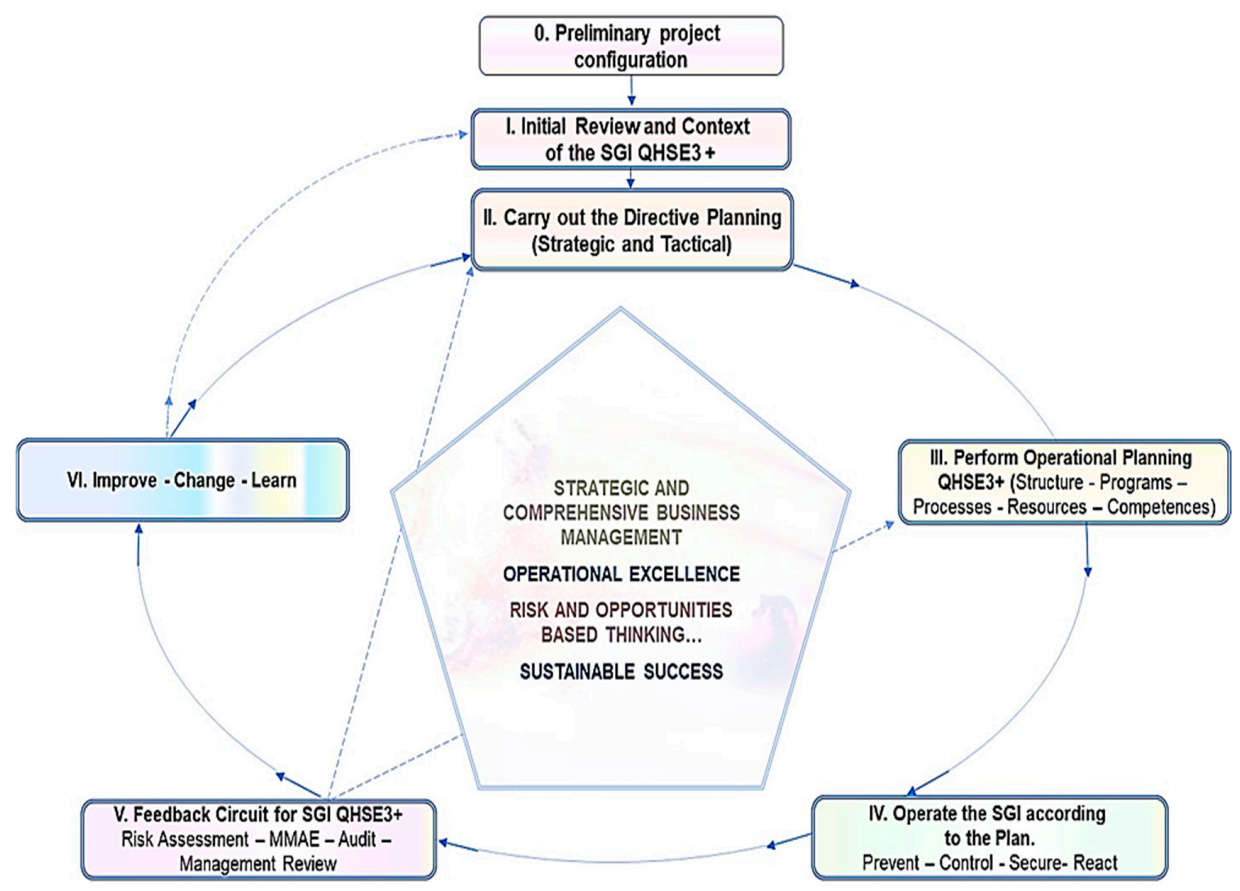

Figure 6. Stages of the implementation project of the CMS QHSE3+. Source: Adapted by the authors from $[22,45,52]$.

\section{Results, Achievements, and Discussion}

Below are the most relevant results obtained during the configuration and development of the concept model of the CMS QHSE3+, and associated tools, as well as in its application in different companies, considering the sequence corresponding to: Problem and objectives trees of the project; Work breakdown structure, implementation route, and project deliverables; Role of energy efficiency in project leverage; General achievements and benefits obtained; Results obtained in terms of energy efficiency. 
In all cases, as confirmed by the data and observations recorded, the fieldwork and the application of the tools and the model in the companies, allowed validating the structural logic, the pedagogical utility, and the expected functional approach.

Thus, although none of the companies submitted to certification with ISO 50001, their management systems were certified or accredited in the quality and regulatory components, and have an integral approach based on strategic management, combined with planning and the operation of the processes, with a perspective of risks in the QHSE3+ components. Thus, in all projects it was possible to show a return on investment, measured in specific terms of vulnerability reduction, reduction of energy consumption, and percentages of progress in compliance against the requirements of the applicable QHSE3+ standards.

It is also important to highlight as a result, the innovative character of the model and tools, which are available to entrepreneurs and the user community of the management systems implementation processes.

\subsection{Problem and Objectives Trees of the Project (Methodology of the Logical Framework)}

At the beginning of any project, we must define the problem to be solved, and identify its causes and consequences to minimize the planning.

The logical framework for Project Management developed by UNIDO, World Bank, the Food and Agriculture Organization, and the IDB, provides a simple methodology for defining the project objective, the large work blocks and types of resources required, and the expected results and impacts $[64,65,67,71]$. We begin the exercise by posing two key questions associated with the research objective:

- What is the central problem that lowers the sustainability of the entrepreneurship and certification projects of the integral management systems of the organization?

- How can we improve the business management, achieve sustainability, and reduce the uncertainty and vulnerability of the business while managing its water and energy usages?

The results of applying this methodology are shown in Figure 7. Shown are the causes and consequences of this situation, and the need to develop a basic work model for management.

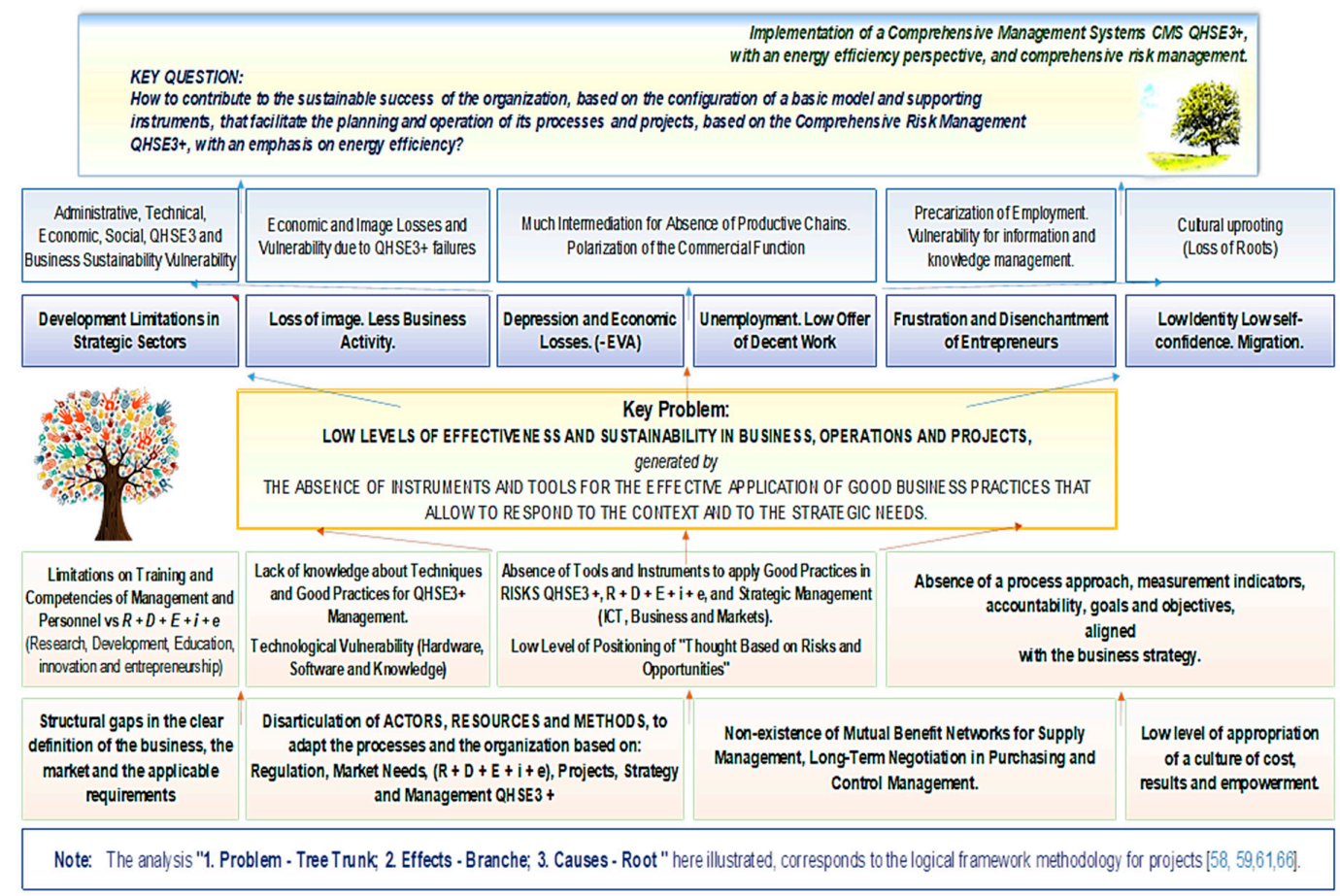

Figure 7. Problem tree analysis. Source: Application of the logical framework for projects $[64,65,67,71]$. 
For this purpose, we require a basic integral approach and easily applied tools by which organizational staff can determine and apply good practices over the cycles of configuration, planning, development and consolidation of their entrepreneurship projects, and hence guarantee sustainability of their companies.

Figure 8 shows the tree begun from the problem tree, which defines the project objective, the expected results, and the most relevant tools, resources and action fronts.

With this approach, a template was generated with instructions for completion, as a tree construction tool, which was used in all projects, as a basis for the identification of the problem, the scope of the project, the activities and key resources required, the objectives and impact indicators. In addition, it was also used as a basis to prepare the Constitution Act or Project Charter of the CMS implementation plan QHSE3+. In this way, it was contributed to companies and entrepreneurs, in terms of clarification of the purposes and general approach of the project.

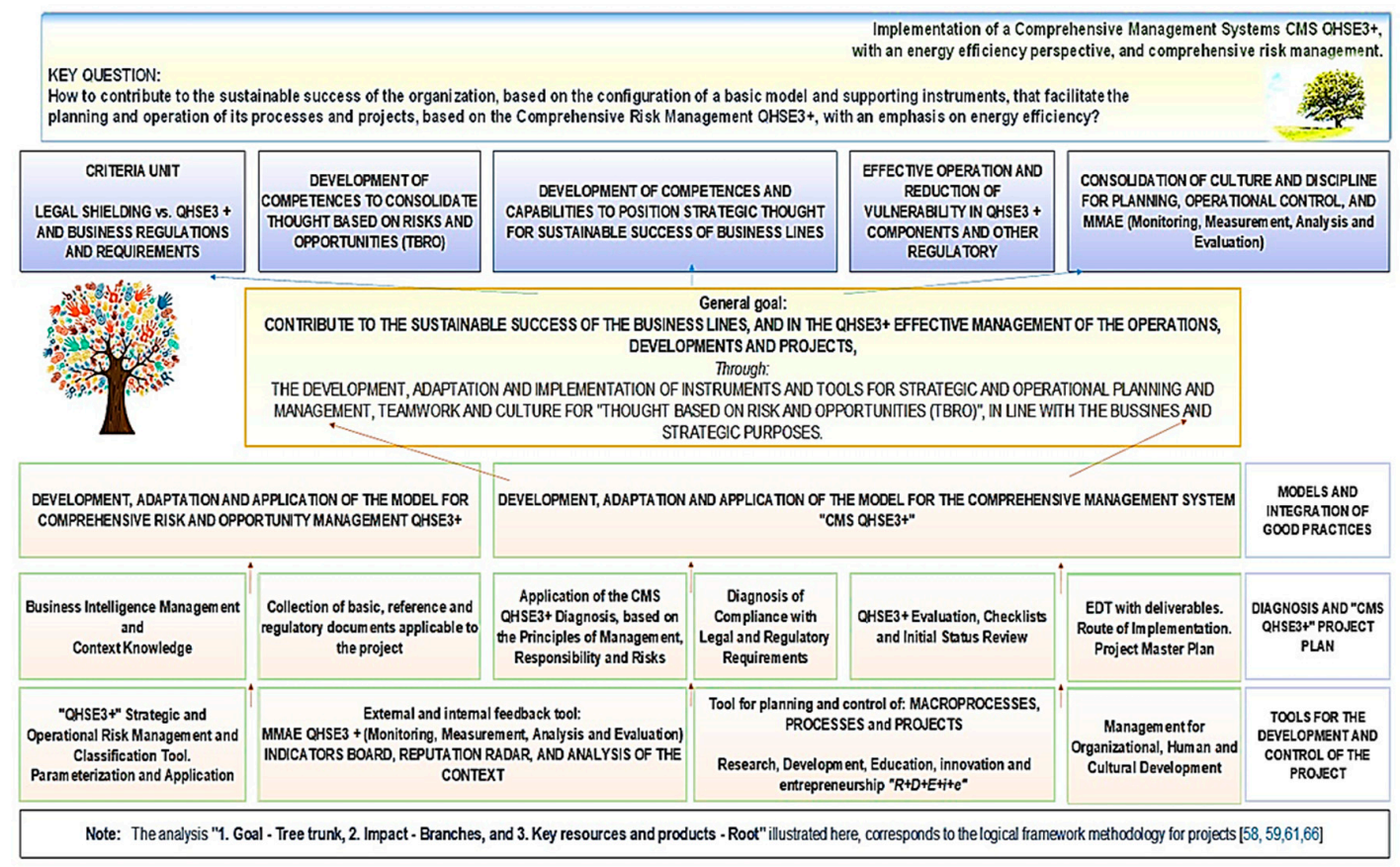

Figure 8. Goal tree analysis. Source: Application of the logical framework for projects $[64,65,67,71]$.

3.2. Work Breakdown Structure, Route, and Deliverables for Implementating the CMS QHSE3+ Project (Emphasis on Key Products Associated with the E2 Component)

One of the most useful concepts in project management is the work breakdown structure (WBS) of packages and work activities. The integration of these packages and activities gives the key deliverables that solve the problem objectives of each project $[65,68,74]$.

Schemes 1 and 2 show the details of the WBS. Deliverables that must be generated at each stage of the project are shown. These tables were configured under a comprehensive QHSE3+ approach, focusing on the energy efficiency component E2. Deliverables are grouped into four axes associated with the balance score card [75], from the bottom up, so that talent and competency Axis 1 corresponds to the last row, and they go up to the extent that the first axis feeds the second, the second to the third, and the third to the fourth, like this:

Axis 1: Human talent and competences, for the development of processes.

Axis 2: Processes that make up a system and generate products and services, directed to clients and interest groups.

Axis 3: Clients and interest groups, which generate income and added value for the strategic and financial purposes of the business 
Axis 4: Strategic and financial.

\begin{tabular}{|c|c|c|c|c|}
\hline$\longrightarrow$ & $\begin{array}{l}\text { PRELIMINARY CONFIGURATION } \\
\text { OF THE PROJECT }\end{array}$ & $\begin{array}{c}\text { INITIAL REVIEW AND CONTEXT } \\
\text { OF CMS QHSE3+ }\end{array}$ & $\begin{array}{c}\text { MANAGEMENT PLANNING OF } \\
\text { CMS QHSE3+ }\end{array}$ & OPERATIONAL PLANNING QHSE3+ \\
\hline $\begin{array}{r}\text { STAGE } \\
\text { and } \\
\text { SUMMARY }\end{array}$ & $\begin{array}{l}\text { ZERO: PROJECT CONFIGURATION } \\
\text { Project Tree (Logical Framework). } \\
\text { Needs and Context of the Project. } \\
\text { Energy Team and QHSE3, WBS. } \\
\text { Project Charter, Project Launch. } \\
\text { Assesment CMS QHSE3+. }\end{array}$ & \begin{tabular}{|c|} 
ONE: CONTEXT AND REVIEW INITIAL \\
Legal and regulatory status. \\
Scope of the CMS and Context Analysis. \\
Gap Analysis QHSE3 and Baseline. KPI \\
Status and Energy Review. WBS, \\
Schedule and \\
Budget of the Project.
\end{tabular} & $\begin{array}{c}\text { TWO: DIRECTIVE PLANNING } \\
\text { Mandate: Principles, Policy, Objectives, } \\
\text { KPI. Strategic Map and Projects. } \\
\text { Contribution of each component } \\
\text { QHSE3+. Framework for Management of } \\
\text { R/O Business Continuity Plan. Planning } \\
\text { and Change Management }\end{array}$ & \begin{tabular}{|} 
THREE: PLAN THE OPERATION AND \\
CONTROL \\
Development of products and lines of \\
business. Adequacy of Resources, \\
Infrastructure and Purchases. Management of \\
R/O in Processes, Projects and MMAE. \\
Management of contingencies and \\
emergencies. Documents of configuration of \\
the CMS and processes
\end{tabular} \\
\hline AXIS & General Project Planning & $\begin{array}{l}\text { Baseline of the CMS QHSE3, and } \\
\text { Detailed Project Planning }\end{array}$ & $\begin{array}{l}\text { Mandate, Strategy and Planning } \\
\text { Directive }\end{array}$ & $\begin{array}{c}\text { Planning of the } \\
\text { "TO DO and TO CONTROL" }\end{array}$ \\
\hline \multirow{5}{*}{ 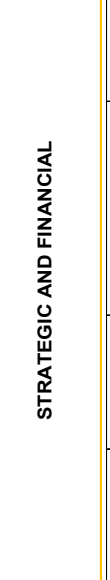 } & $\begin{array}{l}\text { 1. Preliminary definition of the Scope of } \\
\text { CMS QHSE3+ in the Organization. }\end{array}$ & $\begin{array}{l}\text { 7. Analysis of the legal and regulatory } \\
\text { scope applicable to the organization. }\end{array}$ & \multirow{2}{*}{$\begin{array}{l}\text { 14. Official Declaration of the Principles, } \\
\text { Policies, Objectives, and Strategic } \\
\text { Management Indicators for QHSE3+. } \\
\text { It includes: a) The Guidelines that } \\
\text { support the Mandate and Commitment } \\
\text { for CMS QHSE3+), b) The Planning of } \\
\text { the MMAE Directive (Monitoring, } \\
\text { Measurement, Analysis and Evaluation). }\end{array}$} & \multirow{2}{*}{$\begin{array}{l}\text { 22. Ensure the conditions, commitment and } \\
\text { availability of resources and infrastructure for } \\
\text { the implementation and operation of CMS } \\
\text { QHSE3+. }\end{array}$} \\
\hline & \multirow{2}{*}{$\begin{array}{l}\text { 3. Preparation, approval and subscription } \\
\text { of the Project Charter of the CMS } \\
\text { QHSE3+. } \\
\text { (Includes: Configuration of the QHSE3+ } \\
\text { Management Coordination Team, } \\
\text { Energy Team, Assignment of } \\
\text { responsibilities and Approval of } \\
\text { resources). }\end{array}$} & \multirow{2}{*}{$\begin{array}{l}\text { 8. Definition of the QHSE3+ scope } \\
\text { applicable to the CMS for the processes, } \\
\text { headquarters and product-service lines } \\
\text { of the organization, in its different } \\
\text { dimensions. }\end{array}$} & & \\
\hline & & & $\begin{array}{l}\text { 15. General Configuration of the } \\
\text { Reference Framework for the Strategic } \\
\text { R/O Management QHSE3+. } \\
\text { (Provisions, criteria, actors and scope) }\end{array}$ & \\
\hline & $\begin{array}{l}\text { 5. Project launch. Officialization and } \\
\text { Socialization of the Mandate and } \\
\text { Commitment of Senior Management } \\
\text { with respect to CMS QHSE3+ }\end{array}$ & \multirow{2}{*}{$\begin{array}{l}\text { 13. WBS (Work Breakdown Structure), } \\
\text { Schedule and Budget for the CMS } \\
\text { Project QHSE3+ } \\
\text { Structure of breakdown of tasks / } \\
\text { deliverables or General Grid of the } \\
\text { project. } \\
\text { Gap Analysis QHSE3 and Baseline } \\
\text { KPI Status - Performance and Baseline. } \\
\text { Significant Energy Uses. Energy Review }\end{array}$} & $\begin{array}{l}\text { 16. Establishment of the Guidelines and } \\
\text { Plans for Crisis Management and the } \\
\text { Business Continuity Plan }\end{array}$ & \\
\hline & $\begin{array}{l}\text { 6. General Assessment of the Current } \\
\text { State of CMS QHSE } 3+\text { in the } \\
\text { Organization vs. Principles, and } \\
\text { Requirements. Determination of the } \\
\text { Preliminar Gaps. }\end{array}$ & & $\begin{array}{l}\text { 17. Deployment of Guidelines for } \\
\text { Planning and Management of Change } \\
\text { associated with Strategic R/O } \\
\text { Management QHSE3+. }\end{array}$ & \\
\hline \multirow{2}{*}{ 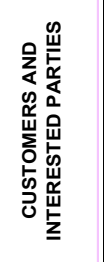 } & \multirow{2}{*}{$\begin{array}{l}\text { 2. Global Analysis of the Needs, and the } \\
\text { Context of the Project with respect to the } \\
\text { Stakeholders, and of their conditions of } \\
\text { Cost - Efficiency and of alignment with } \\
\text { the strategic approach. }\end{array}$} & $\begin{array}{l}\text { 9. Detailed study of the External and } \\
\text { Internal Context of the Stakeholders, } \\
\text { their needs and trends, the relevant } \\
\text { commitments and obligations regarding } \\
\text { the Management of R / O QHSE } 3+\text {. }\end{array}$ & \multirow{2}{*}{$\begin{array}{l}\text { 18. Configuration of the Information and } \\
\text { Communications System of the R/O } \\
\text { Management QHSE3+ } \\
\text { (Alerts, warnings, rendering of accounts, } \\
\text { deployment of indicators, affectation, } \\
\text { perception ... interaction). }\end{array}$} & \multirow{2}{*}{$\begin{array}{l}26 \text { Programs, plans and arrangements for } \\
\text { the management of R/O QHSE } 3+\text {, in the } \\
\text { interaction with clients, contractors and key } \\
\text { partners. }\end{array}$} \\
\hline & & $\begin{array}{l}\text { 10. Consolidated report with } \\
\text { performance statistics, QHSE3+ } \\
\text { (Includes strategic, business and } \\
\text { Preliminary analysis of R/O, Uses and } \\
\text { energy consumption). }\end{array}$ & & \\
\hline \multirow{4}{*}{ 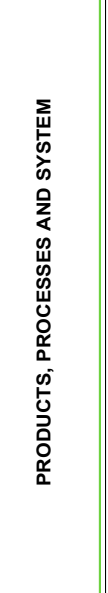 } & & \multirow{4}{*}{$\begin{array}{l}\text { 11. Inventory of the adequacy status } \\
\text { and deployment of the methods, plans } \\
\text { and protocols established for the } \\
\text { Management of R/O QHSE3+ and Work } \\
\text { Plan to consolidate the inventory with } \\
\text { Support Tools. }\end{array}$} & $\begin{array}{l}\text { 19. Review and Consolidation of Support } \\
\text { and Infrastructure Programs and } \\
\text { Projects. (Versus detected gaps) }\end{array}$ & $\begin{array}{l}\text { 23. Plans for the Management of R/O in } \\
\text { corporate projects and in each CMS process. } \\
\text { (Includes: a) The Planning of the Operational } \\
\text { MMAE QHSE3+ (Monitoring, Measurement, } \\
\text { Analysis and Evaluation), b) Plans for data } \\
\text { collection and energy management) }\end{array}$ \\
\hline & & & & $\begin{array}{l}\text { 24. Plans for the management of } R / O \text { in } \\
\text { abnormal conditions, emergency and } \\
\text { contingency for processes and projects, } \\
\text { (Includes provisions for incident } \\
\text { management and reverse logistics). }\end{array}$ \\
\hline & & & & $\begin{array}{l}\text { 25. Consolidation of the Design and } \\
\text { Development of Products and Processes. } \\
\text { It includes analysis, evaluation and } \\
\text { management of R / O QHSE } 3+\text {. Emphasis } \\
\text { on the approach to energy efficiency from } \\
\text { design. }\end{array}$ \\
\hline & & & & $\begin{array}{l}\text { 27. Configuration of the CMS, its processes, } \\
\text { the decisional information system and } \\
\text { external and internal communications. } \\
\text { (Manual or description of CMS QHSE3+ and } \\
\text { the Business Model. Mapping and Process } \\
\text { Planning. Communications Plan). }\end{array}$ \\
\hline \multirow{2}{*}{ 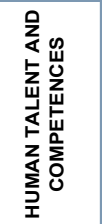 } & \multirow{2}{*}{$\begin{array}{l}\text { 4. Awareness, training and general } \\
\text { communications Plan of CMS QHSE3+ }\end{array}$} & \multirow{2}{*}{$\begin{array}{l}\text { 12. Review of the Implementation of } \\
\text { Phase I of the CMS QHSE3+ } \\
\text { awareness, training and general } \\
\text { communications plan }\end{array}$} & $\begin{array}{l}\text { 20. Officialization of the Plan for the } \\
\text { consolidation of the communication, the } \\
\text { competences, the consultation, and the } \\
\text { Culture for the Management of R/O } \\
\text { QHSE3+. }\end{array}$ & $\begin{array}{l}\text { 28. Review of the Implementation of the } \\
\text { Competence Development, Communication } \\
\text { and Consultation Plan for the Management } \\
\text { of R/O QHSE3+. }\end{array}$ \\
\hline & & & $\begin{array}{l}\text { 21. Definition of the organization for the } \\
\text { CMS QHSE3+ and assignment of } \\
\text { responsibilities. }\end{array}$ & $\begin{array}{l}\text { 29. Review of the Implementation of } \\
\text { Phase II and III of the CMS QHSE3+ } \\
\text { awareness, training and general } \\
\text { communications plan }\end{array}$ \\
\hline
\end{tabular}

Scheme 1. Scheme-work breakdown structure (WBS) for implementing the CMS QHSE3+ project. Stages 0, I, II, and III. Source: [22,45,52]. 


\begin{tabular}{|c|c|c|c|c|}
\hline & OPERATIONAL PLANNING QHSE3+ & OPERATION OF CMS QHSE $3+$ & $\begin{array}{c}\text { EVALUATE THE PERFORMANCE OF } \\
\text { CMS QHSE } 3+\end{array}$ & IMPROVING CMS QHSE3+ \\
\hline $\begin{array}{r}\text { STAGE } \\
\text { and } \\
\text { SUMMARY }\end{array}$ & \begin{tabular}{|} 
THREE: PLAN THE OPERATION AND \\
CONTROL \\
Development of products and lines of \\
business. Adequacy of Resources, \\
Infrastructure and Purchases. Management of \\
R/O in Processes, Projects and MMAE. \\
Management of contingencies and \\
emergencies. Documents of configuration of \\
the CMS and processes
\end{tabular} & $\begin{array}{c}\text { FOUR: OPERATE vs PLANNING } \\
\text { Business deveropopent and compliance of } \\
\text { objectives. Vulnerability reduction (strategic } \\
\text { and operational). Improvement in QHSE } 3+ \\
\text { performance. Integrity and Change } \\
\text { Management Plan Validation of the Manual } \\
\text { of CMS, Maps, Plans, and QHSE3+ } \\
\text { Programs. Records of training and skills } \\
\text { qualification. }\end{array}$ & $\begin{array}{c}\text { FIVE: BUSINESS AND CMS, } \\
\text { QHSE3+FEEDBACK } \\
\text { Audit and Action Plans. Management of NC, } \\
\text { Incidents and PQRS (Petitions, Complaints, } \\
\text { Claims,and Satisfaction), MMAE Strategic } \\
\text { and Opperational. Analysis of uses, } \\
\text { consumption of resources and energy, and } \\
\text { performance of CMS QHSE } 3+\end{array}$ & \begin{tabular}{|c} 
SIX: INNOVATION AND \\
IMPROVEMENT \\
Management review of CMS QHSE3+. \\
Decisions and Challenges for CMS QHSE3+ \\
Review and monitoring of the effectiveness \\
of the actions of adjustment. Innovation, \\
improvement, and progress of CMS.
\end{tabular} \\
\hline AXIS - & $\begin{array}{l}\text { Planning of the } \\
\text { "TO DO and TO CONTROL" }\end{array}$ & Operate according to Plan & $\begin{array}{l}\text { Feedback and } \\
\text { MMAE to performance }\end{array}$ & $\begin{array}{l}\text { Reaction, Innovation and } \\
\text { Improvement }\end{array}$ \\
\hline \multirow{5}{*}{ 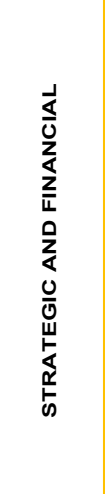 } & \multirow{5}{*}{$\begin{array}{l}\text { 22. Ensure the conditions, commitment and } \\
\text { availability of resources and infrastructure for } \\
\text { the implementation and operation of CMS } \\
\text { QHSE3+. }\end{array}$} & \multirow{3}{*}{$\begin{array}{l}\text { 30. Generation of evidence of the } \\
\text { systematic application and adequacy of: } \\
\text { a) The Plan for the eachievement of of trategic } \\
\text { objectives QHSE3+ and of the Business, } \\
\text { b) The Strategic R/O Management Plan and } \\
\text { the associated corporate projects. } \\
\text { (Emphasis on the measurement and } \\
\text { consecutive registration of KPIs associated } \\
\text { with vulnerability reduction, uses and } \\
\text { consumption of resourcces and energy; and } \\
\text { performance of CMS QHSE3+). }\end{array}$} & \multirow{4}{*}{\begin{tabular}{|l|l|} 
35. Presentation, Analysis and Periodic \\
Review of the consolidated records and the \\
databases associated with the SMAE on the \\
performance of the CMS QHSE $3+$, based on \\
the monitoring of the behavior and trends of \\
the indicators. \\
$\begin{array}{l}\text { 36. Presentation, Analysis and Periodic } \\
\text { Review of the consolidated records and } \\
\text { databases associated with the SMAE on the } \\
\text { performance of the CMS QHSE3+, based on } \\
\text { the measurement of progress and deviations } \\
\text { from the R/O Management Plans }\end{array}$ \\
\end{tabular}} & $\begin{array}{l}\text { 39. Management review of CMS QHSE3+ } \\
\text { (Includes inputs and outputs in terms of } \\
\text { decisions and challenges). }\end{array}$ \\
\hline & & & & $\begin{array}{l}\text { 40. Review and monitoring of the } \\
\text { effectiveness of the actions of adjustment, }\end{array}$ \\
\hline & & & & $\begin{array}{l}\text { QHSE3+ and the General Plan of the } \\
\text { Strategic R/O Management QHSE3+, with } \\
\text { emphasis on. }\end{array}$ \\
\hline & & \multirow{2}{*}{$\begin{array}{l}\text { 31. Configuration and validation of the Plan } \\
\text { for the Management of the Integrity of the } \\
\text { CMS QHSE3+, changes and innovation, } \\
\text { supported by the Plan for the Management } \\
\text { of the R/O. }\end{array}$} & & $\begin{array}{l}\text { Project component of CMS QHSE3+, } \\
\text { b. Improvements in the Operational } \\
\text { component of Processes and Contingency }\end{array}$ \\
\hline & & & $\begin{array}{l}\text { 37. Presentation, Analysis and Periodic } \\
\text { Review of consolidated records. }\end{array}$ & conditions, for the elements QHSE3+. \\
\hline 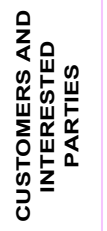 & $\begin{array}{l}26 \text { Programs, plans and arrangements for } \\
\text { the management of R/O QHSE3+, in the } \\
\text { interaction with clients, contractors and key } \\
\text { partners. }\end{array}$ & & & \\
\hline \multirow{4}{*}{ 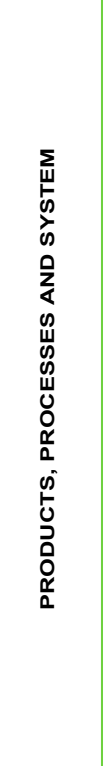 } & $\begin{array}{l}\text { 23. Plans for the Management of R/O in } \\
\text { corporate projects and in each CMS process. } \\
\text { (Includes: a) The Planning of the Operational } \\
\text { MMAE QHSE3+ (Monitoring, Measurement, } \\
\text { Analysis and Evaluation), b) Plans for data } \\
\text { collection and energy management) }\end{array}$ & \multirow{2}{*}{$\begin{array}{l}\text { 32. Generation of evidence on the } \\
\text { systematic application and adequacy of: } \\
\text { a) Operational R/O Management Plan for } \\
\text { projects and processes, with emphasis on } \\
\text { the effectiveness of control over the R/O. } \\
\text { b) Actions for updataing and systematic } \\
\text { management of the ROO, taking into account } \\
\text { incidents, developments and context } \\
\text { changes. }\end{array}$} & & \\
\hline & $\begin{array}{l}\text { 24. Plans for the management of R/O in } \\
\text { abnormal conditions, emergency and } \\
\text { contingency for processes and projects, } \\
\text { (Includes provisions for incident } \\
\text { management and reverse logistics). }\end{array}$ & & & \\
\hline & $\begin{array}{l}\text { 25. Consolidation of the Design and } \\
\text { Development of Products and Processes. } \\
\text { It includes analysis, evaluation and } \\
\text { management of R / O QHSEE +. Emphasis } \\
\text { on the approach to energy efficiency from } \\
\text { design. }\end{array}$ & \multirow{2}{*}{$\begin{array}{l}\text { 33. Systematic application and validation of } \\
\text { the provisions contained in the Manual of } \\
\text { the CMS, and in the documents that define } \\
\text { processes, plans and programs in the } \\
\text { QHSE3+ field. }\end{array}$} & & \\
\hline & $\begin{array}{l}\text { 27. Configuration of the CMS, its processes, } \\
\text { the decisional information system and } \\
\text { external and internal communications. } \\
\text { (Manual or description of CMS QHSE } 3+\text { and } \\
\text { the Business Model. Mapping and Process } \\
\text { Planning. Communications Plan). }\end{array}$ & & & \\
\hline \multirow{2}{*}{ 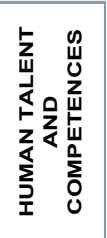 } & $\begin{array}{l}\text { 28. Review of the Implementation of the } \\
\text { Competence Development, Communication } \\
\text { and Consultation Plan for the Management } \\
\text { of R/O QHSE3+. }\end{array}$ & \multirow{2}{*}{$\begin{array}{l}\text { 34. Records of the training carried out and } \\
\text { the qualification of the competences }\end{array}$} & \multirow{2}{*}{$\begin{array}{l}\text { 38. Review of the implementation of Phase } \\
\text { III of the awareness, training and general } \\
\text { communications plan } \\
\text { of CMS QHSE3+. (Includes projections and } \\
\text { continuous reformulation).. }\end{array}$} & \\
\hline & $\begin{array}{l}\text { 29. Review of the Implementation of } \\
\text { Phase II and III of the CMS QHSE } 3+ \\
\text { awareness, training and general } \\
\text { communications plan }\end{array}$ & & & \\
\hline
\end{tabular}

Scheme 2. Scheme-WBS for the implementation of CMS QHSE3+. Stages III, IV, V, and VI. Source: [22,45,52]. 
It is important to note that in addition to the general conception of the CMS QHSE3+ model, this WBS has been one of the innovative tools with the greatest impact and utility in the projects carried out by the authors, both for the consultants, as well as for those responsible for the administration and the effective development of CMS implementation projects, on the side of companies; taking into account that it allows:

- To have a complete vision of the project and its stages, as well as the deliverables that must be generated in each one.

- To make specific adjustments based on the status of each company, specific applicable requirements, the regulations of the business, or exclusions.

- To have a good general starting point to structure the master plan or project schedule, and control its effective development.

- Align the strategic management of the business with the operational and integral risk approach QHSE3+ of the processes, insofar as the stages follow a PDCA cycle, which considers strategic planning, operational planning, "thought based on risks and opportunities", the process approach, the monitoring, measurement, analysis and evaluation MMAE, and the improvement actions accordingly.

\subsubsection{Stage Zero: Preliminary Project Configuration}

Applying the project management tools of the logical framework and PMBOK, this stage constructs the problem tree and the objectives, the WBS, the project scope and charter, and the project needs and context. It also preliminarily assesses the CMS QHSE3+ and organizes the project development, including the energy team.

The phases and detailed route of the project are presented in Schemes 1 and 2. The created WBS displays the sequence of the deliverables that meet the QHSE3+ requirements along each axis and in each phase of the project.

Reference documents, tree templates of the logical framework, the project charter, and the support tools can be found in [22,52,58,59,68,70], in ISO 50001:2018, ISO 17741:2016; ISO 17743:2016; ISO 50047:2016; ISO 50004:2014, and at energy.gov, energystar.gov, and cleanenergyministerial.org. See also Scheme A1 of Appendix A.

\subsubsection{Stage I. Initial Review and Context of CMS QHSE3+}

Stage I includes the initial context study, the analysis of the legal and regulatory status, the analysis of the gap between the QHSE3+ and the baseline, the status determination of the KPIs, and an energy review. This phase also determines the scope of the CMS and defines the project in more detail, considering the WBS, schedule, and budget of the project. In parallel with stages 0 and I, the support activities related to awareness, training and the general communications of the CMS QHSE3+ are planned, developed, and evaluated.

Reference documents, templates, examples, good practices and methods of energy savings, context analysis and reputation, legal requirements management, initial status review, baseline, KPI status, and project master plans are provided in the following sources:

- Energy efficiency component E2: ISO50047:2016, ISO50004:2014, ISO50006:2014, and ISO 50015:2014.

- Environmental component E: ISO14004:2016, ISO14001:2015, ISO14031:2013, and ISO 14005:2010.

- HS component of Occupational Safety and Health: ISO 45001:2018, and OHSAS 18002:2008.

- Projects, forums, website, and publications in progress for each component: TC 176 (Q), TC 283 (HS), TC 207 (E), TC 301 (E2), developed by the ISO TCs.

- Complementary components (+): see the forums and website of the ISO 27000 families for information security and ISO 22000 for food security. 
- See also www.iso.org/iso-45001-occupational-health-and-safety.html; www.lms.quaratechnology. com in the Bank of Knowledge of the GIR Guide, www.iso.org/committee/54960.html, and http: //www.iso27000.es/sgsi.html.

\subsubsection{Stage II. Management Planning of CMS QHSE3+}

Stage II formulates the strategic initiatives for sustainable success and competitiveness, and defines the objectives and corporate projects.

This stage highlights the following results that guide the strategic direction: policy mandate, the principles and CMS approach, the strategic map and the QHSE3+ projects, planning for strategic R/O management, planning for business continuity, and planning for change management and innovation. For these results, one can consult the methods, techniques and examples referenced in Stage I; further information is available in ISO 31000:2018, ISO 9004:2018, ISO DIS 22301:2019, and [76,77].

\subsubsection{Stage III. Operational Planning of QHSE3+}

This stage plans the specifications and methods that operate and control the CMS QHSE3+ processes. The following key deliverables must be met: provisions and projects for product development and lines of business, management of interaction with clients, the market and stakeholders, planning and adequation of resources, infrastructure and purchases, the identification, evaluation, and management of R/O QHSE3+ in processes and projects, MMAE planning, management of contingencies and emergencies, and documents for configuring the CMS and processes. In this stage, one can consult the references listed in Stage II, along with the techniques, methods and examples in the following sources: IEC FDIS 31010:2019, ISO TR 31004:2013, SA/SNZ HB 436:2013, ISO 14031:2013, ISO/IEC 27002:2013, ISO 14006:2011, and UNE 166002:2006. See also www.euskadinnova.net, www.hse.gov.uk/risk, www.ifsqn.com/forum, www.iaf.nu, and [32-38,78].

For specific technical aspects of the operational planning of energy management, prediction of energy consumption, planning, and optimization of the Energy Management Systems in particular contexts, and reducing the vulnerability to risks of the energy efficiency (E2) component, the reader is referred to [79-88].

\subsubsection{Stage IV. Operation of CMS QHSE3+}

This stage applies the dispositions planned in the previous stages. In an integral approach, it outputs the deliverables and evidences related to business development, objective compliances, and vulnerability reduction (strategic and operational).

This stage also evaluates the KPIs related to improvement of QHSE3+, and validates the CMS manual, maps, plans, QHSE3+ programs, and records of training and skills qualifications of the staff.

In additional to references listed in stages 0 , I, II, and III, the following websites can be accessed at this stage: www.iso27000.es/sgsi.html, www.lmsquaratechnology, and www.iso27001security.com/ $\mathrm{html} /$ toolkit.html. These sites, which are publicly available, present a series of examples of templates, documents, manuals, plans, maps and toolkits.

\subsubsection{Stage V. Evaluating the Performance of CMS QHSE3+}

This stage provides the feedback on the performance of CMS QHSE3+. The feedback considers the planning and development of audit cycles, the follow-up and closure of corrective and improvement actions, management of non-conformities, incidents and reporting systems (requests, claims, and satisfaction), strategic and operational management of MMAE in the CMS, the QHSE3+ components and business lines of the CMS, and the analysis of uses, resources, and energy.

The annexes of the standard guidelines provide the implementations of the components, and the QHSE3+ requirements standards referenced in the previous section provide the MMAE guidelines. The aforementioned website portals include the tools and checklists for MMAE, and comprehensive diagnostics and audits of the QHSE3+ components. 


\subsubsection{Stage VI. Improving the CMS QHSE3+}

This stage presents the challenges and decisions on the future of the CMS QHSE3+ and each business line. The conclusions are based on the above-mentioned feedback mechanisms and a managerial review. This stage monitors the adequacy, convenience, effectiveness, innovation, and progress of the company, its energy and environmental performance, its advances in integral security, and the maturity of its CMS QHSE3+.

Valid recommendations and methods for this stage and for each QHSE3+ component in this stage are available in the reference documents listed in the previous steps. This stage closes and restarts the operation cycle of the CMS, and integrates the challenges and decisions with the strategic planning actions and corporate projects, as well as with the operational planning of processes and products.

During the implementation processes of a CMS, the energy efficiency component faces many barriers and difficulties that are closely linked to pessimism, preliminary resistance to change, or because in some cases implementing of energy efficiency is not cost-effective or has little financial benefits.

These difficulties are generally resolved under guiding examples and consistent planning, which require discipline, participation, innovation, commitment, and sustained leadership. In addition to delivering technical benefits, such dedication will optimize the financial performance of the organization and generate a culture willing to measure and assume responsibility for its results and achievements, implement energy savings and risk prevention, and research alternatives for sustainable success and mutual benefit [12,20,22,83-92].

\subsection{Role of Energy Efficiency (E2) in the Leverage of CMS QHSE3+ and R/O Management}

In recent decades, the increase in unit costs of energy, fuels, and water has been evident for manufacturing and service companies, for the commerce sector, and for the community in general too. This has been caused by various factors among that includes the increase in population and demand as well as the depletion of water resources and organic fuels.

Accordingly, the use of water and energy has a significant impact on the costs and expenses of those organizations in which their operations involve a considerable and permanent demand of the resource. At the strategic level, many organizations are seeking alternatives that reduce the vulnerability to price volatility, and lower the reliance on oil, fuels, water, and energy in general.

However, as pointed out by Cooremans [93], a systematic and continuous dedication to investments and projects in energy management has not yet been generalized within investment maps and corporate cultures. The exceptions are manufacturing organizations or operations using furnaces, mills, or transport infrastructure, in which energy or fuel is among the most important items in the budget.

In fact, investments and energy risks are not always labeled in strategic projects, and although many governments have stipulated the development of energy-saving plans and projects as a legal requirement, only a few have effectively managed their energy usage in practice. Most companies merely impose controls on their billed consumption as a secondary administrative measure [91,92].

Notwithstanding, when organizations adapt their culture toward "thought based on risks and opportunities", and develop projects that improve their energy efficiency, they are rewarded with an attractive investment return that can leverage other important investments through comprehensive management 


\subsection{General Achievements and Benefits of the Research}

The present research will provide entrepreneurs, SMEs and interested sectors with the following services:

- A matrix that pedagogically presents the logical and thematic structure of the ISO 50000 family of international standards (Scheme A1 Appendix A). The main and complementary blocks display the vocabulary, reference framework, requirements, and general guidelines. The matrix includes the short- and medium-term strategic approach of the work plan of the TC 301 Committee, which emphasizes good practices of a general nature and those of specific sectors. By adopting these practices, organizations can measure their energy-saving performances and deploy and promote the ISO 50001:2018.

- An inventory of the aspects not considered in the current revision was presented in a graphical operation model of the EnMS and the CMS QHSE3+. This model illustrates the correlation, application logic, and relationship with the structure of the reviewed document. It emphasizes the need for a comprehensive management system and risk management that considers the strategic management level, projects, process operations, and new business developments, products and services (Section 2.1.7 and Figure 2).

- A tool that constructs the problem tree was demonstrated on the CMS QHSE3+ implementation project, with identification of the problem causes and implications.

- As a general application, the tree-constructing tool was demonstrated on the central objective of the project. The expected results, identification of the key issues, and the blocks corresponding to the developmental work packages of the project were revealed (see Figures 7 and 8 of Section 3.1).

- The implementation route of CMS QHSE3 + was established using the WBS of the implementation project, which allows us to visualize, correlate and understand the stages, deliverables and axes of the project. The WBS was obtained as follows: (i) Human talent and competencies, (ii) processes and management system products, iii) market and stakeholders, and iv) financial and strategic management. From this WBS, one can develop tools for the master control of projects (see Section 3.2 and Schemes 1 and 2).

- The implementation route was described with reference to the documents and website portals that provide the guidelines, examples, templates, and tools for developing and applying the deliverables of the project (numbered 1-40 in Schemes 1 and 2; see Section 3.2).

- The obtained achievements and results will determine the course of the investigations and the subsequent actions for disseminating, expanding, and enlarging the instruments generated by the research, thereby promoting sustainable success in entrepreneurship efforts.

\subsection{Results Related to Energy Efficiency}

The model and its support instruments were preliminarily evaluated in six types of organization: family compensation services, health services in a municipal hospital and a local clinic, a pharmaceutical laboratory, port operations, and glass production.

The model improved the focus, clarity, ease of application, consistency, didactic utility, and general logical structures of the organizations. The achievements are listed below and summarized in Schemes 3-5.

The model and its support instruments were preliminary evaluated in six types of organizations: Family compensation services, health services in a municipal hospital, a local clinic, a pharmaceutical laboratory, port operations, and glass production. 


\begin{tabular}{|c|c|c|c|c|c|c|c|c|c|c|c|}
\hline \multicolumn{12}{|c|}{ CHARACTERISTICS OF THE SELECTED COMPANIES' CMS. ACHIEVEMENTS IN COMPONENT E2 } \\
\hline & COMPONENTS QHSE3+ & $\mathbf{Q}$ & HS & E & E2 & + & $\mathbf{Q}$ & HS & E & E2 & + \\
\hline & $\begin{array}{l}\text { TYPE OF ORGANIZATION } \\
\text { FEATURE CONSIDERED }\end{array}$ & \multicolumn{5}{|c|}{ Family Compensation Fund. } & \multicolumn{5}{|c|}{$\begin{array}{l}\text { Municipal Hospital } \\
\text { (Health Services). }\end{array}$} \\
\hline 1 & $\begin{array}{l}\text { Comprehensive Approach of the } \\
\text { Management System. }\end{array}$ & \multicolumn{5}{|c|}{$\begin{array}{l}\text { CMS focused on the Regulatory } \\
\text { Framework and the Strategy }\end{array}$} & \multicolumn{5}{|c|}{$\begin{array}{l}\text { CMS focused on the Regulatory } \\
\text { Framework and the Strategy }\end{array}$} \\
\hline & $\begin{array}{l}\text { Components of the Management System. } \\
\text { certified or accredited by the national }\end{array}$ & $\begin{array}{l}Q \\
\text { (c) }\end{array}$ & & & & $\begin{array}{c}+ \\
(\mathbf{R})\end{array}$ & $\begin{array}{l}Q \\
\text { (c) }\end{array}$ & & & & $\begin{array}{c}+ \\
(\mathrm{R})\end{array}$ \\
\hline 2 & $\begin{array}{l}\text { GMP - FDA = Good Manufacture Practices } \\
\text { Food and Drug Administration } \\
\text { BASC = Business Anti-Smuggling } \\
\text { Coalition } \\
\text { ISPS = International Ship and Port Facility } \\
\text { Security }\end{array}$ & \multicolumn{5}{|c|}{$\begin{array}{l}\text { 1. Q: Certified ISO } 9001 \\
\text { 2. +: Accredited by the national } \\
\text { regulatory body. }\end{array}$} & \multicolumn{5}{|c|}{$\begin{array}{l}\text { 1. Q: Certified ISO } 9001 \\
\text { 2. +: Accredited by the national } \\
\text { regulatory body }\end{array}$} \\
\hline & & & & & E2 & & & & & E2 & \\
\hline 3 & $\begin{array}{l}\text { Approach and status of the E2 Energy } \\
\text { Efficiency Component. according to ISO } \\
50001\end{array}$ & \multicolumn{5}{|c|}{$\begin{array}{l}\text { 1. Basic Energy Saving Program } \\
\text { (Legal) } \\
\text { 2. Risk approach of } \\
\text { Comprehensive Management } \\
\text { System CMS. } \\
\text { 3. They have no interest in being } \\
\text { certified with ISO } 50001 .\end{array}$} & \multicolumn{5}{|c|}{$\begin{array}{l}\text { 1. Basic Energy Saving Program } \\
\text { (Legal) } \\
\text { 2. They have no interest in being } \\
\text { certified with ISO } 50001 \text {. }\end{array}$} \\
\hline 4 & $\begin{array}{l}\text { Degree of E2 component implementation } \\
\text { (According to checklist based on ISO } \\
\text { 50001: 2018). }\end{array}$ & \multicolumn{5}{|c|}{$\begin{array}{l}\text { LOW IMPLEMENTATION } \\
\text { LEVEL: (31\%) }\end{array}$} & \multicolumn{5}{|c|}{$\begin{array}{l}\text { LOW IMPLEMENTATION } \\
\text { LEVEL: (35\%) }\end{array}$} \\
\hline 5 & $\begin{array}{l}\text { REDUCTION OF VULNERABILITY in } \\
\text { E2 RISKS associated with Energy } \\
\text { Efficiency. YEAR } 1 .\end{array}$ & \multicolumn{5}{|c|}{$18.0 \%$} & \multicolumn{5}{|c|}{$16.4 \%$} \\
\hline 6 & $\begin{array}{l}\text { REDUCTION OF VULNERABILITY in } \\
\text { E2 RISKS associated with Energy } \\
\text { Efficiency. YEAR } 2 .\end{array}$ & \multicolumn{5}{|c|}{$4.6 \%$} & \multicolumn{5}{|c|}{$3.6 \%$} \\
\hline 7 & $\begin{array}{l}\text { REDUCTION OF VULNERABILITY in } \\
\text { E2 RISKS associated with Energy } \\
\text { Efficiency. YEAR } 3 .\end{array}$ & \multicolumn{5}{|c|}{$5.2 \%$} & \multicolumn{5}{|c|}{$4.6 \%$} \\
\hline 8 & $\begin{array}{l}\text { Examples of the applied Energy Efficiency } \\
\text { Good Practices. which generated the } \\
\text { greatest impact on reducing vulnerability. }\end{array}$ & \multicolumn{5}{|c|}{$\begin{array}{l}\text { 1. Campaigns. Training and } \\
\text { Supervision for E2. } \\
\text { 2. Optimization of the cold network } \\
\text { for Food and Beverages. } \\
\text { 3. Control and minimization of } \\
\text { energy use in accommodation and } \\
\text { Food and Beverage areas. } \\
\text { 4. Automatic control and } \\
\text { alternatives for energy saving in } \\
\text { lighting. (Adequacy of covers and } \\
\text { roofs). } \\
\text { 5. Optimization in the ventilation } \\
\text { and cooling of the bar and } \\
\text { kitchens. }\end{array}$} & \multicolumn{5}{|c|}{$\begin{array}{l}\text { 1. Redesign. Automation of lighting } \\
\text { and air conditioning systems. Use } \\
\text { of secondary sources of natural } \\
\text { light and solar panels. } \\
\text { 2. Optimization and maintenance of } \\
\text { ventilation and conditioning } \\
\text { systems in hospital and patient } \\
\text { care areas. Cold rooms. } \\
\text { 3. Control and minimization of } \\
\text { energy use in areas and operations } \\
\text { of washing. sanitation and patient } \\
\text { care. } \\
4 \text {. Maintenance and adaptation of } \\
\text { steam boilers. and cold equipment } \\
\text { (Chillers). } \\
\text { 5. Monitoring and Action on } \\
\text { Monthly Energy Consumption vs. } \\
\text { Beds - day - occupieds. }\end{array}$} \\
\hline 9 & $\begin{array}{l}\text { REDUCTION OF PER CAPITA ENERGY } \\
\text { CONSUMPTION. BETWEEN YEAR } 1 \text { AND } \\
\text { YEAR } 3\end{array}$ & \multicolumn{5}{|c|}{$16.3 \%$} & \multicolumn{5}{|c|}{$38.4 \%$} \\
\hline
\end{tabular}

Scheme 3. Scheme of CMS characteristics of Companies 1 and 2 (achievements in component E2). 
CHARACTERISTICS OF THE SELECTED COMPANIES' CMS. ACHIEVEMENTS IN COMPONENT E2

\begin{tabular}{|c|c|c|c|c|c|c|c|c|c|c|c|}
\hline & COMPONENTS QHSE3+ & $\mathbf{Q}$ & HS & E & E2 & + & $\mathbf{Q}$ & HS & E & E2 & + \\
\hline & $\begin{array}{l}\text { TYPE OF ORGA } \overrightarrow{\text { NIZATION }} \\
\text { FEATURE CONSIDERED }\end{array}$ & & (Heal & línic & & & & $\begin{aligned} & \text { Pha } \\
& \text { La }\end{aligned}$ & & $\begin{array}{l}\text { itical } \\
\text { ry. }\end{array}$ & \\
\hline 1 & $\begin{array}{l}\text { Comprehensive Approach of the } \\
\text { Management System. }\end{array}$ & $\begin{array}{l}\text { CMS } \\
\text { Fran }\end{array}$ & focuse & $\begin{array}{l}\text { on } \mathrm{t} \\
\text { ad th }\end{array}$ & $\begin{array}{l}\text { Regu } \\
\text { Strate }\end{array}$ & $\begin{array}{l}\text { atory } \\
\text { ly }\end{array}$ & CMS & ocuse & on $\mathrm{t}$ & Strate & \\
\hline & $\begin{array}{l}\text { Components of the Management System. } \\
\text { certified or accredited by the national }\end{array}$ & $\begin{array}{l}Q \\
\text { (c) }\end{array}$ & $\begin{array}{l}\text { HS } \\
\text { (c) }\end{array}$ & $\begin{array}{l}E \\
\text { (c) }\end{array}$ & & $\begin{array}{c}+ \\
(\mathbf{R})\end{array}$ & $\begin{array}{c}Q \\
\text { (c) }\end{array}$ & $\begin{array}{l}\text { HS } \\
\text { (c) }\end{array}$ & $\begin{array}{l}E \\
\text { (c) }\end{array}$ & & $\begin{aligned}+(\mathrm{c}) \\
(\mathrm{GMP})\end{aligned}$ \\
\hline
\end{tabular}
regulatory body.

(c) = certified; $(R)=$ accredited

2 GMP - FDA = Good Manufacture Practices -

Food and Drug Administration

BASC = Business Anti-Smuggling

Coalition

ISPS = International Ship and Port Facility Security

\section{Q: Certified ISO 9001 \\ 2. HS: Certified ISO 45001 \\ 3. E: Certified ISO 14001 \\ 4. +: Accredited by the national \\ regulatory body}

1. Q: Certified ISO 9001

2. HS: Certified ISO 45001

3. E: Certified ISO 14001

4. + : Accredited by the national

regulatory body

5. +: GMP certification by FDA
Approach and status of the E2 Energy

3 Efficiency Component. according to ISO 50001

1. Basic Energy Saving Program

4 (According component implementatior 50001: 2018).

REDUCTION OF VULNERABILITY in

5 E2 RISKS associated with Energy Efficiency. YEAR 1.

REDUCTION OF VULNERABILITY in

6 E2 RISKS associated with Energy Efficiency. YEAR 2.

REDUCTION OF VULNERABILITY in

7 E2 RISKS associated with Energy

Efficiency. YEAR 3.

Examples of the applied Energy Efficiency

8 Good Practices. which generated the greatest impact on reducing vulnerability.

REDUCTION OF PER CAPITA ENERGY 9 CONSUMPTION. BETWEEN YEAR 1 AND YEAR 3 (Legal)

2. MMAE and Energy

Management Plans Integrated to the EMS ISO 14001 certificate.

3. They have not considered

certification with ISO 50001

MEDIUM IMPLEMENTATION LEVEL: (56\%)

$(56 \%)$
LEVEL: (59\%)

1. Basic Energy Saving Program (Legal)

2. MMAE and Energy Management

Plans Integrated to the EMS ISO

14001 certificate.

3. They have not considered

certification with ISO 50001.

MEDIUM IMPLEMENTATION

\begin{tabular}{|c|c|}
\hline $14.8 \%$ & $9.6 \%$ \\
\hline $18.6 \%$ & $9.4 \%$ \\
\hline $12.4 \%$ & $8.2 \%$ \\
\hline $\begin{array}{l}\text { 1. Redesign of facilities and } \\
\text { application of intelligent lighting } \\
\text { and air conditioning systems. } \\
2 \text {. Insulation of "hot" pipes. walls } \\
\text { and roofs } \\
\text { 3. Optimization and maintenance } \\
\text { of ventilation and conditioning of } \\
\text { hospital and service areas. Special } \\
\text { attention to cold rooms. } \\
\text { 4. Campaigns and mechanisms to } \\
\text { achieve the systematic application } \\
\text { of good practices by users and } \\
\text { patients. } \\
5 \text {. New Eco-efficient Machine and } \\
\text { Boiler Room. (With investment } \\
\text { incentive). } \\
6 \text {. Reduction of losses of electrical } \\
\text { energy. by transformation. }\end{array}$ & $\begin{array}{l}\text { 1. Isolation of white areas and } \\
\text { warehouses to optimize conditioning } \\
\text { and cooling. } \\
\text { 2. Redesign of external and internal } \\
\text { networks and installations. with } \\
\text { intelligent air conditioning and } \\
\text { lighting systems. } \\
\text { 3. Optimization and maintenance of } \\
\text { ventilation and conditioning of gray } \\
\text { areas. } \\
\text { 4. Training and disciplinary measures } \\
\text { for continuity in the application of } \\
\text { good practices. } \\
5 \text {. Replacement of obsolete } \\
\text { equipment for eco-efficient } \\
\text { conversion. (With investment } \\
\text { incentive). } \\
6 \text {. Devices in doors and windows to } \\
\text { prevent leaks. } \\
\text { 7. Cleaning and replacement of filters } \\
\text { in air conditioning units. }\end{array}$ \\
\hline $42.6 \%$ & $27.4 \%$ \\
\hline
\end{tabular}

Scheme 4. Scheme of CMS characteristics of Companies 3 and 4 (Achievements in component E2). 


\begin{tabular}{|c|c|c|c|c|c|c|c|c|c|}
\hline \multicolumn{10}{|c|}{ CHARACTERISTICS OF THE SELECTED COMPANIES' CMS. ACHIEVEMENTS IN COMPONENT E2 } \\
\hline \multirow{2}{*}{\multicolumn{2}{|c|}{$\begin{array}{l}\text { TYPE OF ORGANIZATION } \\
\text { FEATURE CONSIDERED }\end{array}$}} & HS & $\mathrm{E}$ & E2 & $\mathbf{Q}$ & HS & $E$ & E2 & + \\
\hline & & \multicolumn{3}{|c|}{$\begin{array}{c}\text { Port Operation } \\
\text { (Logistics Services). }\end{array}$} & \multicolumn{5}{|c|}{$\begin{array}{l}\text { Manufacturing } \\
\text { (Glass Containers). }\end{array}$} \\
\hline 1 & $\begin{array}{l}\text { Comprehensive Approach of the } \\
\text { Management System. }\end{array}$ & \multicolumn{3}{|c|}{ CMS focused on the Strategy. } & \multicolumn{5}{|c|}{ CMS focused on the Strategy. } \\
\hline & $\begin{array}{l}\text { Components of the Management System. } \\
\text { certified or accredited by the national }\end{array}$ & $\begin{array}{l}\text { HS } \\
\text { (c) }\end{array}$ & $\begin{array}{l}E \\
\text { (c) }\end{array}$ & $\begin{array}{l}+(\mathrm{c}) \\
(\mathrm{R})\end{array}$ & $\begin{array}{l}Q \\
\text { (c) }\end{array}$ & & $\begin{array}{l}E \\
\text { (c) }\end{array}$ & & $\begin{array}{l}+(\mathrm{c}) \\
(22 \mathrm{k})\end{array}$ \\
\hline 2 & $\begin{array}{l}\text { (c) = certifled; }(R)=\text { accredited } \\
\text { GMP }- \text { FDA = Good Manufacture Practices } \\
\text { Food and Drug Administration } \\
\text { BASC = Business Anti-Smuggling } \\
\text { Coalition } \\
\text { ISPS = International Ship and Port Facility } \\
\text { Security }\end{array}$ & \multicolumn{3}{|c|}{$\begin{array}{l}\text { 1. Q: Certified ISO } 9001 \\
\text { 2. HS: Certified ISO } 45001 \\
\text { 3. E: Certified ISO } 14001 \\
\text { 4. +: Accredited by the national } \\
\text { regulatory body } \\
\text { 5. +: Certifications BASC and ISPS }\end{array}$} & \multicolumn{5}{|c|}{$\begin{array}{l}\text { 1. Q: Certified ISO } 9001 \\
\text { 2. E: Certified ISO } 14001 \\
\text { 3. +: Certified BASC } \\
\text { 4. +: Certified ISO } 22000\end{array}$} \\
\hline & & & & E2 & & & & E2 & \\
\hline 3 & $\begin{array}{l}\text { Approach and status of the E2 Energy } \\
\text { Efficiency Component. according to ISO } \\
50001\end{array}$ & \multicolumn{3}{|c|}{$\begin{array}{l}\text { 1. Basic Energy Saving Program } \\
\text { (Legal) } \\
\text { 2. MMAE and Energy Management } \\
\text { Plans Integrated to the EMS ISO } \\
14001 \text { certificate. } \\
\text { 3. They have not considered } \\
\text { certification with ISO } 50001 .\end{array}$} & \multicolumn{5}{|c|}{$\begin{array}{l}\text { 1. Basic Energy Saving Program } \\
\text { (Legal) } \\
\text { 2. MMAE and Energy Management } \\
\text { Plans Integrated to the EMS ISO } \\
14001 \text { certificate. } \\
\text { 3. They have not considered } \\
\text { certification with ISO } 50001 \text {. } \\
\text { 4. The company has a World E2 } \\
\text { Program. }\end{array}$} \\
\hline 4 & $\begin{array}{l}\text { Degree of E2 component implementation } \\
\text { (According to checklist based on ISO } \\
\text { 50001: 2018). }\end{array}$ & \multicolumn{3}{|c|}{$\begin{array}{l}\text { LOW IMPLEMENTATION } \\
\text { LEVEL: (38\%) }\end{array}$} & \multicolumn{5}{|c|}{$\begin{array}{c}\text { MEDIUM-HIGH } \\
\text { IMPLEMENTATION LEVEL: (69\%) }\end{array}$} \\
\hline 5 & $\begin{array}{l}\text { REDUCTION OF VULNERABILITY in } \\
\text { E2 RISKS associated with Energy } \\
\text { Efficiency. YEAR } 1 .\end{array}$ & \multicolumn{3}{|c|}{$10.8 \%$} & \multicolumn{5}{|c|}{$18.6 \%$} \\
\hline 6 & $\begin{array}{l}\text { REDUCTION OF VULNERABILITY in } \\
\text { E2 RISKS associated with Energy } \\
\text { Efficiency. YEAR } 2 .\end{array}$ & \multicolumn{3}{|c|}{$12.6 \%$} & \multicolumn{5}{|c|}{$11.5 \%$} \\
\hline 7 & $\begin{array}{l}\text { REDUCTION OF VULNERABILITY in } \\
\text { E2 RISKS associated with Energy } \\
\text { Efficiency. YEAR } 3 .\end{array}$ & \multicolumn{3}{|c|}{$9.5 \%$} & \multicolumn{5}{|c|}{$14.3 \%$} \\
\hline 8 & $\begin{array}{l}\text { Examples of the applied Energy Efficiency } \\
\text { Good Practices. which generated the } \\
\text { greatest impact on reducing vulnerability. }\end{array}$ & \multicolumn{3}{|c|}{$\begin{array}{l}\text { 1. Incorporation of energy } \\
\text { efficiency in the strategy. } \\
\text { 2. Training. supervision and } \\
\text { measures to apply Good Practices } \\
\text { E2. } \\
\text { 3. Replacement of fuels and } \\
\text { development of alternative } \\
\text { mixtures (Reduction of carbon } \\
\text { footprint and consumption of KWh } \\
\text { per container). } \\
\text { 4. Greater control over own and } \\
\text { outsourced consumption } \\
\text { 5. Measurement and Reduction of } \\
\text { Electricity and Heat Loss. } \\
\text { 6. Planning. Execution and Control } \\
\text { of maintenance and renewal of } \\
\text { obsolete equipment. } \\
\text { 7. Efficient lighting. }\end{array}$} & \multicolumn{5}{|c|}{$\begin{array}{l}\text { 1. Global strategic challenge to } \\
\text { reduce fuel consumption by at least } \\
50 \% \text {. } \\
\text { 2. Campaigns. Training and } \\
\text { Supervision for E2. } \\
\text { 3. Planning. standardization. } \\
\text { mastery and advanced control of the } \\
\text { furnace operation processes for the } \\
\text { melting and shaping of glass } \\
\text { containers. } \\
\text { 4. Eco-efficient packaging design. } \\
\text { Life cycle analysis. } \\
5 \text {. Automatic control and alternatives } \\
\text { for energy saving in lighting. (Natural } \\
\text { and Solar Panels). } \\
6 \text {. Optimization in ventilation and } \\
\text { conditioning. } \\
\text { 7. Reduction of consumption in the } \\
\text { supply chain. }\end{array}$} \\
\hline 9 & $\begin{array}{l}\text { REDUCTION OF PER CAPITA ENERGY } \\
\text { CONSUMPTION. BETWEEN YEAR } 1 \text { AND } \\
\text { YEAR } 3\end{array}$ & \multicolumn{3}{|c|}{$34.4 \%$} & \multicolumn{5}{|c|}{$22.4 \%$} \\
\hline
\end{tabular}

Scheme 5. Scheme of CMS characteristics of Companies 5 and 6 (Achievements in component E2). 
The model allowed improving the focus, clarity, ease of application, consistency, educational utility, and general logical structures of organizations, in relation to their comprehensive management system. The achievements are summarized in Schemes 3-5 that have been configured as follows:

In Scheme 3, the results corresponding to the first two companies are grouped: Family compensation services and health services in a municipal hospital

In Scheme 4, the results corresponding to the following two companies are grouped: Health services in a local clinic and pharmaceutical laboratory

In Scheme 5 the results corresponding to the following two companies are grouped: Logistic services of operation in port and glass production.

The three tables have 9 blocks of rows, which correspond to the categories of analysis considered, ranging from the comprehensive approach of the management system, in Row 1 , to the reduction in energy consumption per capita, in Row 9. The achievements obtained are listed below:

- Row 1 describes the current approach of each CSM. The manufactures of pharmaceutical products and the family health and compensation services are regulated. In all regulated cases, the management system focuses on the regulatory framework and the planned strategy. In the production of glass containers, the regulation ensures safety in the food chain.

- $\quad$ Row 2 indicates the certification (c) statuses of the quality $(\mathrm{Q})$ components of the six companies in the group, along with the accreditation by the regulatory body in the companies covered by a regulatory framework.

- In Row 2, four of the six companies were certified in the environmental (E) component, three were certified in the occupational health and safety (HS) component, and two were certified in the management of illegal trade, drug trafficking, and terrorism (BASC+ component).

- The blocks of Rows 2 and 3 also reveal that although none of the six companies were certified in the energy efficiency (E2) component of ISO 50001:2018, they all adopted energy management programs under the approach of integral risk management (MMAE dynamics of their EMS and a legal obligation to implement energy saving plans). Among this group of companies, one was certified with good manufacturing process by the Food and Drug Administration, and another was certified with ISO 22000.

- Row 4 shows the degree of implementation of ISO 50001:2018 under the classification criteria, which require evidence of improvement to $100 \%$ in each requirement. The results range from a low level of implementation (31\% of companies) to a medium-high level of implementation (69\% of companies). None of the six companies were interested in acquiring the formal ISO 50001 certification.

- Rows 5-7 present the average reductions in vulnerability to energy efficiency risks in the first, second, and third years, respectively. The results ranged from $9.60 \%$ to $18.60 \%$ in the first year, from $9.4 \%$ to $11.5 \%$ in the second year, and from $4.60 \%$ to $14.30 \%$ in the third year.

Although these behaviors show no regular pattern because they are governed by different variables and conditions, the percentage reduction is expected to be highest in the first few years of implementation.

The vulnerability reduction indicator is calculated as

$$
\% \text { DismVul }=\left[\sum_{i=1}^{n}\left(P o_{i}\right)\left(G o_{i}\right)-\sum_{i=1}^{n}\left(P f_{i}\right)\left(G f_{i}\right)\right] /\left[\sum_{i=1}^{n}\left(P o_{i}\right)\left(G o_{i}\right)\right]
$$

where $\mathrm{DismVul}$ denotes the percentage decrease in vulnerability after implementing anti-risk measures, $P o_{i}$ and $\mathrm{Go}_{i}$ are the initially assessed possibility and gravity, respectively, and $P f_{i}$ and $G f_{i}$, are the final possibility and gravity, respectively, after adopting the planned measures.

- Row 8 presents the most relevant examples of good practices that most effectively reduced the vulnerability and improved the energy efficiency of each company. Good practices were of three 
types: (a) Actions of a technical or technological nature associated with cleaning, maintenance, adjustment, commissioning and renovation of equipment and machinery; (b) Actions of planning, measurement management, monitoring, and control; and (c) Actions focused on training and the development of habits, behaviors, culture, and awareness.

- Most of the good practices adopted by this group of companies are embodied in the standards and guidelines of EMAS, and are highlighted at the sector level by Laskurain et al. [26,93].

- Finally, Row 9 presents the average reduction valuations of the per capita energy consumptions between year 1 and year 3 . The energy reductions were satisfactory and ranged from $16.30 \%$ to $42.60 \%$.

\section{Conclusions}

In the first instance, it can be affirmed that the objectives of the research that supports this paper have been met, taking into account the products generated during the development of the research, and the actions taken for the application and validation of the model, methods and tools configured for its implementation in different companies of goods and services (Schemes 3-5).

In this way, simple pedagogical instruments are made available to the business sector and SMEs, so that they apply in a generalized manner the good practices of the international ISO standards, in the CMS QHSE3+ comprehensive management systems, with a holistic perspective of risk management, opportunities and energy efficiency, at strategic level, of business lines and operational processes.

On the other hand, with the degree of extension and thematic development of this paper, the objectives set out in Section 1 have also been fulfilled, in order to make an inventory of the main aspects not included in ISO 50001:2018, and of the critical needs of organizations that implement the comprehensive management systems CMS QHSE3+, of having a simple, holistic fusion/integration route, in harmony with the nature of each business and its target markets, based on a conceptual model that can be implemented through a project in which the deliverables contribute effectively towards the sustainable success of the entrepreneurial efforts.

With this purpose, it is emphasized that it is precisely management that gives a comprehensive character to the system. In addition, the system should not simply be a combination or addition of components, and should be fully aligned with the nature, purposes and strategic focus of the business, ensuring that in all cases energy efficiency management is included in the risk maps and the portfolio of strategic projects of each business, and that the "thought based on risks and opportunities" be part of the institutional culture and daily life of people.

It is precisely in this last point associated with the awareness and appropriation of the good practices QHSE3+, where we have the Achilles heel.

From this investigation, we have shown that a comprehensive management system with a QHSE3+ perspective can be applied in companies, with quite encouraging results in terms of vulnerability reductions ranging from $4.60 \%$ to $18.60 \%$ in a heterogeneous group of companies, or, with significant reductions in energy consumption, which can financially support continuity in projects to consolidate CMS.

On the other hand, SMEs continue to go bankrupt and do not exceed 5 years of life. Entrepreneurship efforts have a high percentage of failure, while energy wastage, global warming, excessive use of resources, and irrational consumerism remain constant and there are very few states with strong, mandatory, and punitive legal regulations on energy efficiency.

Against this background, from the community of consultants, teachers, entrepreneurs, workers, and researchers related to the CMS QHSE3+, we must continue to develop tools and strategies to promote the massification and widespread use of good practices for project management, energy efficiency, and comprehensive management for sustainable success with meaning.

Author Contributions: Conceptualization, P.P.P.-O., J.C.G.-D., A.P.-R., and G.C.-Z.; methodology, P.P.P.-O., J.C.G.-D., A.P.-R., and G.C.-Z.; validation, P.P.P.-O. and G.C.-Z.; formal analysis, A.P.-R. and P.P.P.-O.; investigation, 
P.P.P.-O., J.C.G.-D., A.P.-R., and G.C.-Z.; data curation, A.P.-R. and P.P.P.-O..; writing-original draft preparation, P.P.P.-O.; writing-review and editing, P.P.P.-O., J.C.G.-D., A.P.-R., and G.C.-Z.; visualization, A.P.-R. and G.C.-Z.; supervision, P.P.P.-O., J.C.G.-D.

Funding: This research received no external funding.

Acknowledgments: We express our gratitude for the support received, to CAJACOPI ATLÁNTICO, QUARA Group, ASTEQ Technology, Simón Bolivar University, the Universitat Politècnica de València, SANTO TORIBIO Business Group, and to all the personalities and companies who offered us their contributions and their valuable points of view.

Conflicts of Interest: The authors declare no conflict of interest.

\section{Abbreviations}

ANSI
BASC
CEM
CMS
Component E - 14k
Component E2 - 50k
Component HS - 45k
Component Q - 9k
E2
EMAS
EnMS
GIR
GMP - FDA
HLS
ICT
IDB
IPEEC
ISO

American National Standards Institute

Business Anti-Smuggling Coalition

Clean Energy Ministerial

Comprehensive Management System

Environmental Management - ISO 14001

Energy Efficiency Management - ISO 50001

Health and Safety Management Component - ISO 45001

Quality Management Component - ISO 9001

Energy efficiency

Eco-Management and Audit Scheme

Energy Management System

Comprehensive risk management (In spanish)

Good Manufacture Practices - Food and Drug Administration

High Level Structure

Information and Comunication Technologies

Inter-American Development Bank

International Partnership for Energy Efficiency Cooperation

International Organization for Standardization

ISO DIS - ISO FDIS

Draft International Standard (DIS) or Final draft International Standard (FDIS) of the International Organization for Standardization ISO

ISO TR

Technical Report of ISO.

ISO/IEC

International Organization for Standardization / International Electrotechnical

Commission

ISO/TC

ISPS

Technical Standardization Committee

KPI

MMAE

International Ship and Port Facility Security

Key Performance Indicators

OHSAS

Monitoring, Measurement, Analysis and Evaluation

Occupational Health and Safety Assessment Specification

PDCA

PMBOK

PMI

QHSE3+

$\mathrm{R} / \mathrm{O}$

Cycle Plan - Do - Check - Act, or Plan - Do - Check - Adjust

Project Management Body of Knowledge

Project Management Institute

Quality, Safety and Health in the workplace, Environmental management, Energy

Efficiency and other risk components

rdis

Risks and opportunities

International Design Research Network

Hand Book edited by National Standardization Organizatios of Australia and

SA/SNZ HB

New Zealand.

SCADA

Supervisory Control and Data Acquisition

SMEs

TBRO

Small and medium-sized enterprises

UNIDO

WBS

Thought based on Risks and Opportunities

United Nations Industrial Development Organization

Work Breakdown Structure 


\section{Appendix A. Logical Structure of the ISO 50000 Family of Standards}

Taking into account that through this paper reference is made to the guides, examples and support that can be accessed with the ISO 50000 family standards, we present in this Annex A, its logical structure, including classification and basic approach of the current standards, and of those that are under development since the TC 301 Committee. Scheme A1 summarizes the development of the standards planned by ISO TC 301. This matrix illustrates the structural logic of the ISO 50000 family of standards and the expected strategic approach of its development.

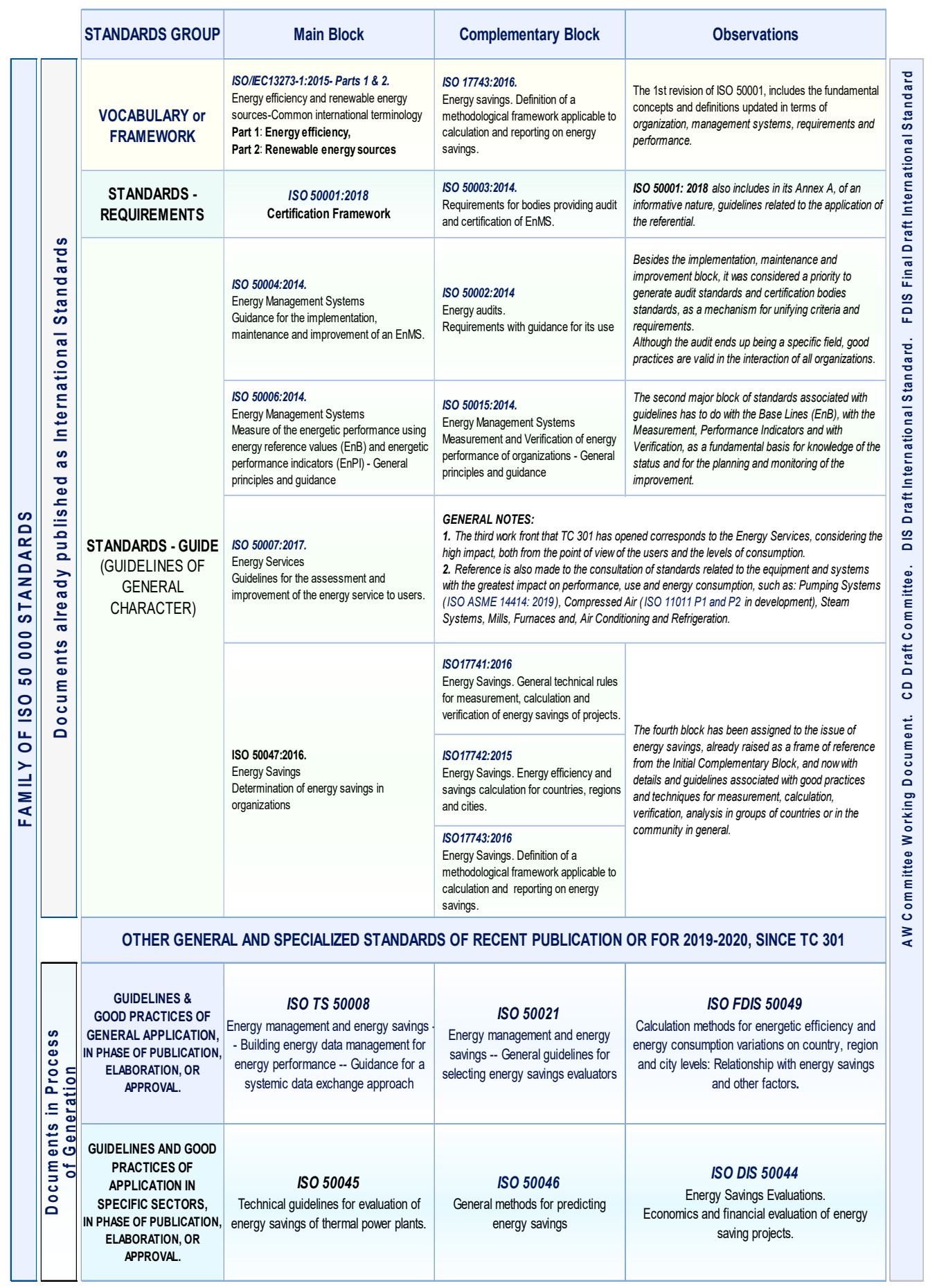

Scheme A1. Scheme of the Structure of the ISO 50000 Family: Blocks and development perspective. Source: Realized by the authors, based on the ISO/TC 301 website [1]. 
When planning the development of the ISO 50000 family (50k family) of standards, the Technical Commission ISO/TC 301 considered the following aspects:

- The 50k family includes standards for the terminology vocabulary of energy efficiency and renewable energy sources: ISO/IEC 3273:2015, Parts 1 and 2.

- In Section 3 of ISO 50001:2018, the vocabulary is complemented with management terms that are grouped into blocks, promoting alignment of the terms used in the ISO 50001 review with the vocabulary of the ISO 9000, ISO 45000, ISO 14000 and ISO 500000 families.

- The chapters are organized and sequenced under a high-level hierarchical structure established by ISO. The aim is to simplify the creation of new standards and ease the implementation of multiple standards.

- The current version of ISO 50001:2018 includes guidelines on its use and application.

- For each requirement of ISO 50001:2018, ISO 50004:2014 and ISO 50001:2018 provide guidelines for the implementation, maintenance and improvement of an EnMS, giving particular examples in their annexes.

- The work plan of the TC 301 committee focuses only on short and medium term outcomes, and evolves through measurement of feedback, evaluation, and performance indicators, and the management of energy savings.

The guidelines developed by the ISO/TC 301 are intended to promote the application of good practices, particularly, the implementation of EnMS in high-impact, specialized sectors. These sectors were determined by studying the needs of the parties and the characteristics of the contexts associated with TC 301 management [1,4].

Since 2010, the United Nations Industrial Development Organization (UNIDO) and the International Partnership for Energy Efficiency Cooperation (IPEEC) have been convoking the ministers of state and world authorities on energy matters, proposing different initiatives that will accelerate the transition towards clean energy through the "Global Challenge for Energy Efficiency". As outlined in the Clean Energy Ministerial (CEM) [5], this challenge is met through the following action fronts:

- The "Clean Energy Revolution," supported by the "Women for Clean Energy, Education and Empowerment" initiative."

- The fast deployment of electric vehicles and smart electric networks worldwide that facilitate the measurement, control and improvement of energy-saving initiatives, in parallel with government actions for deploying low-carbon energy sources.

- Improved energy efficiency in the industry and service sectors.

- Multilateral promotion of solar and wind energy, sustainable development initiatives with hydroelectric energy, and the Atlas bioenergy program utilizing biofuels, biomass, and other biological resources.

According to CEM statistics and their projections for 2030, industrial and commercial sectors could save over 600 billion dollars by implementing ISO 50001, and could reduce their carbon emissions by 6.5 billion metric tons [5].

\section{Appendix B. Application of the Model CMS QHSE3+ and the Route of Implementation}

This illustration shows the stages of the CMS QHSE3+ implementation project. For each stage it is summarized: The purpose, the key deliverables, the references and the support links that contribute with examples, templates and guidelines for their best application by the energy management managers and/or by those responsible for other components of the CMS QHSE3+.

The approach presented here was applied in a family compensation fund, in a clinic and a municipal hospital, in a pharmaceutical laboratory, in a port logistics operator, and in a glass container production plant. The most relevant results are presented in Section 3, Schemes 3-5. 


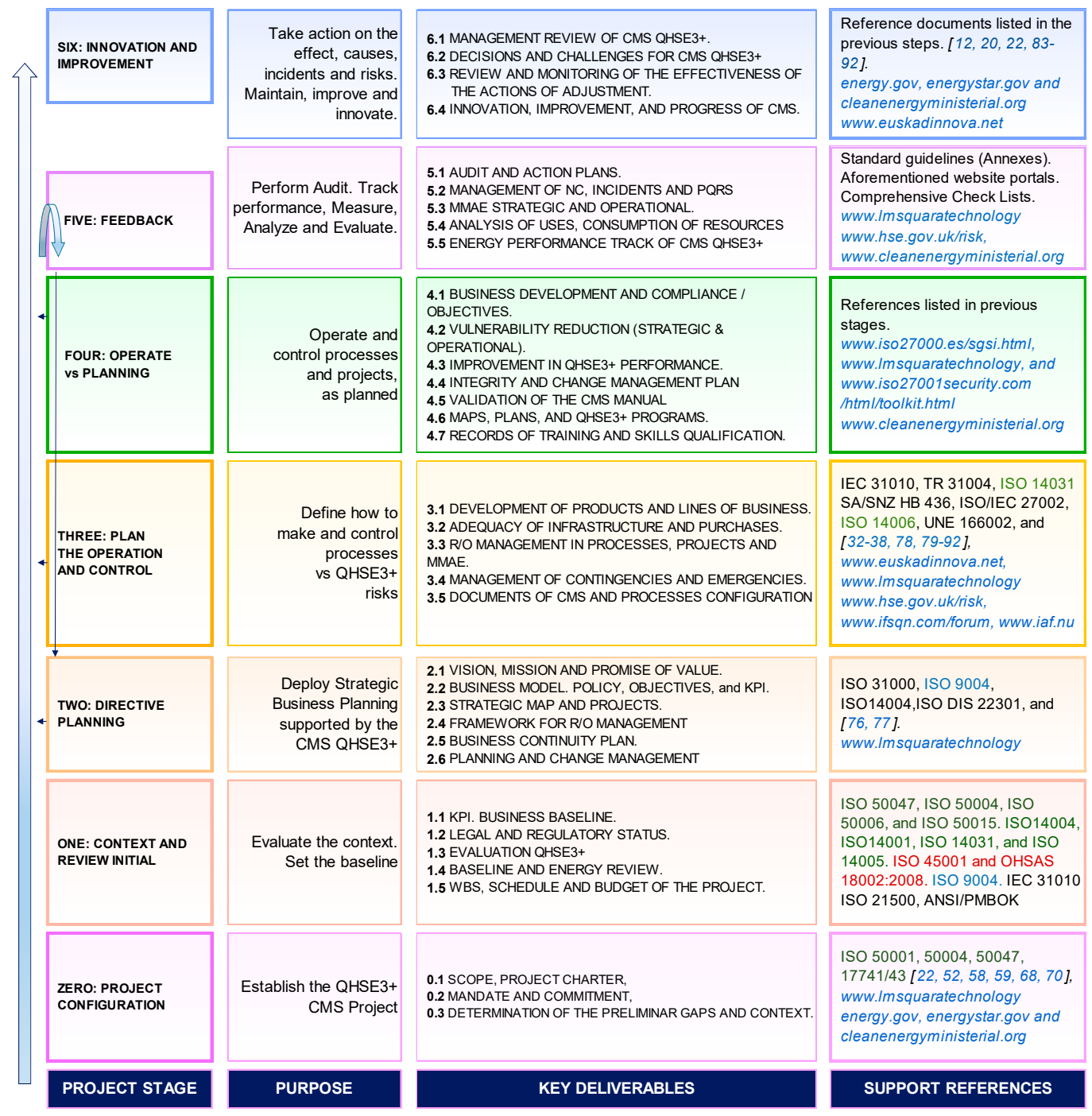

Scheme A2. Summary of the CMS QHSE3+ Implementation approach. Support References.

\section{References}

1. ISO/TC 301 Energy Management and Energy Savings. Strategic Business Plan 2017. 2 October 2017. Available online: https://isotc.iso.org/livelink/livelink/fetch/2000/2122/687806/ISO_TC_301_Energy_management_and_ energy_saving.pdf?nodeid=19278553\&vernum=-2 (accessed on 30 March 2019).

2. Gasiorowski, E. Five years on-Did live up to its promise? ISO Focus 2017, 119, 14-19.

3. ISO/IEC. Directives and Policies Ninth Edition, Part 2. Official Rules to Develop an ISO Standard. 2018. Available online: www.iso.org/directives-and-policies.html (accessed on 26 February 2019).

4. ISO/TC 301 Energy Management and Energy Savings. Standards by ISO/TC 301. 2019. Available online: https://www.iso.org/committee/6077221.html (accessed on 30 August 2019).

5. Clean Energy Ministerial CEM. CEM Advancing Clean Energy Together, Ministerial Meetings. 2019. Available online: https://www.cleanenergyministerial.org/events-Clean-Energy-Ministerial.CEM01toCEM10 (accessed on 2 September 2019).

6. Organization for Economic Co-Operation and Development OECD. 6 September 2018. Available online: https://stats.oecd.org/index.aspx?queryid=70734 (accessed on 30 August 2019).

7. DG GROW. Strategic Plan 2016-2020. Bruxelles: CEE. 2017. Available online: https:/trade.ec.europa.eu/ doclib/docs/2016/august/tradoc_154919.pdf (accessed on 26 July 2019).

8. Muñoz, P. The distinctive importance of sustainable entrepreneurship. CUOCIEnt 2013, 2, 1-6. [CrossRef] 
9. Parrish, B.D. Sustainability-driven entrepreneurship: Principles of organization design. J. Bus. Ventur. 2010, 25, 510-523. [CrossRef]

10. The Standish Group. Chaos Report. 2015. Available online: http://www.laboratorioti.com/2016/05/16/informedel-caos-2015-chaos-report-2015-bien-malfueron-los-proyectos-ano-2015/ (accessed on 20 September 2019).

11. Arévalo, G. Cluster Support Programs in Latin America. Lessons Learned from the IDB Experience; Fourth Latin American Cluster Congress; CLAC TCI-Mendoza Government: Mendoza, Argentina, 2009; pp. 1-16. Available online: https://publications.iadb.org/es/publicacion/15838/programas-de-apoyo-clusters-en-america-latinalecciones-aprendidas-de-la (accessed on 21 May 2019). (In Spanish)

12. Uriarte, R.; Gil, M.; Valenzuela, J.; Ceballos, J. Methodology for the successful integration of an Energy Management System to an Operational Environmental System. Sustainability 2017, 9, 1304.

13. Aven, T. Risk assessment and risk management: Review of recent advances on their foundation. EJOR 2016, 253, 1-13. [CrossRef]

14. Oliva, F.L. A maturity model for enterprise risk management. Int. J. Prod. Econ. 2016, 173, 66-79. [CrossRef]

15. Paraschivescu, A.O. Risk management and quality management an integrate aproach. ETC 2016, $19,55-61$.

16. Thekdi, S.; Aven, T. An enhanced data-analytic framework for integrating risk management and performance management. Reliab. Eng. Syst. Safe 2016, 156, 277-287. [CrossRef]

17. Dereinda, F.; Greenwood, L. Environmental Management System Risks and Oportunities: A Case Study in Pertamina Geothermal Energy Area Kamojang. In Proceedings of the World Geothermal Congress Pertamina, Melbourne, Australia, 19-25 April 2015; pp. 1-13.

18. Krohn, B.; Aven, T. A new perspective on how to understand, asses and manage risk and the unforeseen. Reliab. Eng. Syst. Safe 2014, 121, 1-10.

19. Wilson, J.; Campbell, L. ISO 9001:2015: The evolution and convergence of quality management and knowledge management for competitive advantage. Total Qual. Manag. Bus. 2018, 29, 1-16. [CrossRef]

20. Ciravegna Martins da Fonseca, L. ISO 14001:2015: An improved tool for sustainability. JIEM 2015, 8, 37-50. [CrossRef]

21. Cosgrove, J.; Littlewood, J.; Wilgeroth, P. Development of a framework of key performance indicators to identify reductions in energy consumption in a medical devices production facility. Int. J. Ambient Energy 2018, 39, 202-210. [CrossRef]

22. Poveda, P.; Cañón, G. Guide for Integral Risk Management. Understand, Decide and Act Intelligently for Sustainable Success; ICONTEC: Bogotá, Colombia, 2015; ISBN 9789588585512. (In Spanish)

23. Castrillón, R.; Rey, J.; Velasco, E.; San José, A.; Rey, F. Analysis of the Methodology to Obtain Several Key Indicators Performance (KIP), by Energy Retrofitting of the Actual Building to the District Heating Fuelled by Biomass, Focusing on nZEB Goal: Case of Study. Energies 2019, 12, 93. [CrossRef]

24. Haeri, A. Proposing a quantitative approach to measure the success of energy management systems in accordance with ISO 50001: 2011 using an analytical hierarchy process (AHP). Energyequipsys 2017, 5, 349-355.

25. Chiu, T.; Lo, S.; Tsai, Y. Establishing an integration-energy-practice model for improving energy performance indicators in ISO 50001 energy management systems. Energies 2012, 5, 5324-5339. [CrossRef]

26. Laskurain, I.; Ibarloza, A.; Larrea, A.; Allur, E. Contribution to energy management of the main standards for environmental management systems: The case of ISO 14001 and EMAS. Energies 2017, 10, 1758. [CrossRef]

27. Al-Sakkaf, S.; Kassas, M.; Khalid, M.; Abido, M. An energy management system for residential autonomous dc microgrid using optimized fuzzy logic controller considering economic dispatch. Energies 2019, $12,1457$. [CrossRef]

28. Zobel, T.; Malmgren, C. Evaluating the Management System Approach for Industrial Energy Efficiency Improvements. Energies 2016, 9, 774. [CrossRef]

29. Laskurain, I.; Heras, I.; Casadesús, M. Fostering renewable energy sources by standards for environmental and energy management. Renew. Sustain. Energy Rev. 2015, 50, 1148-1156. [CrossRef]

30. Stoeglehner, G.; Niemetz, N.; Kettl, K. Spatial dimensions of sustainable energy systems: new visions for integrated spatial and energy planning. Energy Sustain. Soc. 2011, 1, 1-9. [CrossRef]

31. Godet, M. The Art of Scenarios and Strategic Planning: Tools and Pitfalls. Technol. Soc. 2000, 65, 3-22.

32. Calvillo, C.; Sánchez-Miralles, A.; Villar, J. Energy management and planning in smart cities. Renew. Sustain. Energy Rev. 2016, 55, 273-287. [CrossRef] 
33. Morvaj, B.; Lugaric, L.; Krajcar, S. Demonstrating Smart Buildings and Smart Grid Features in a Smart Energy City. In Proceedings of the 3rd International youth conference on energetics (IYCE), Leiria, Portugal, 7-9 July 2011; pp. 1-8.

34. Blaauwbroek, N.; Nguyen, P.; Konsman, M.; Shi, H.; Kamphuis, R.; Kling, W. Decentralized Resource Allocation and Load Scheduling for Multicommodity Smart Energy Systems. IEEE Trans. Sustain. Energy 2015, 6, 1505-1514. [CrossRef]

35. Mao, M.; Jin, P.; Hatziargyriou, N.; Chang, L. Multiagent-based hybrid energy management system for microgrids. IEEE Trans. Sustain. Energy 2014, 5, 938-946. [CrossRef]

36. Carli, R.; Dotoli, M. Decentralized control for residential energy management of a smart users' microgrid with renewable energy exchange. IEEE/CAA J. Autom. Sin. 2019, 6, 641-656. [CrossRef]

37. Hosseini, S.; Carli, R.; Dotoli, M. Robust Day-Ahead Energy Scheduling of a Smart Residential User Under Uncertainty. In Proceedings of the 18th European Control Conference (ECC), Naples, Italy, 25-28 June 2019.

38. Roy, S.; Goswami, S.; Pal, A.; Kumar, A.; Singh, H.; Biswas, M.; Ghosh, B.; Mandal, R. Application of Modified Particle Swarm Optimization Technique for Economic Scheduling of a Complex Micro Grid with Renewable Energy Sources. In Proceedings of the 2nd International Conference on Trends in Electronics and Informatics (ICOEI), Tirunelveli, India, 11-12 May 2018.

39. ISEC LTD-ISO/IEC JTC1/SC 27. The ISO 27k Forum. 2018. Available online: https://www.iso27001security. $\mathrm{com} / \mathrm{html} /$ iso27000.html (accessed on 1 June 2019).

40. IEC. IEC FDIS 31010:2010. Risk Assessment Techniques; IEC: Geneva, Switzerland, 2010. Available online: http://ehss.moe.gov.ir/getattachment/f7de1f2a-7559-49b5-8b97-c69b13fa17a9/31010-FDIS-(RiskAssessment-Technics) (accessed on 2 September 2019).

41. ISO. ISO 50004:2014: Guide for the Implementation, Maintenance and Improvement of an EnMS; ISO/IEC: Geneva, Switzerland, 2014.

42. ISO. ISO 50006:2014: Measuring Energy Performance Using Energy Baselines (EnB) and Energy Performance Indicators (EnPI)—General Principles and Guidance; ISO/IEC: Geneva, Switzerland, 2014.

43. International Organization for Standardization. ISO 50015:2014: Measurement and Verification of Energy Performance of Organizations—General Principles and Guidance; ISO/IEC: Geneva, Switzerland, 2014.

44. ISO. ISO 31000:2018. Risk Management-Guidelines; ISO/IEC: Geneva, Switzerland, 2018.

45. Poveda, P.; García-Díaz, J.; Hernandis, B. Application of the Systemic Method to the Design of a Conceptual Model for Comprehensive Management Systems QHSE3 + in SMEs. In IFDP'16-Systems and Design: Beyond Processes and Thinking. Electronic Book Proceedings; Universitat Politècnica de València: Valencia, Spain, 2016; pp. 651-664. (In Spanish)

46. Cathalifaud, A.; Osorio, F. Introduction to the Basic Concepts of General Systems Theory. Cinta de Moebio. 1998. Available online: http://www.redalyc.org/articulo.oa?id=10100306 (accessed on 10 September 2019). (In Spanish).

47. Von Bertalanffy, L. The theory of open systems in physics and biology. Science 1959, 111, 23-29. Available online: https://www.jstor.org/stable/1676073 (accessed on 10 September 2019). [CrossRef]

48. Guerrero, M.; Hernandis, B. An approach to the representation of a product's form and appearance: study on design attributes. Innovar 2018, 28, 25-39.

49. Hernandis, B.; Iribarren, E. Systems Modeling New Products Design to Systemic Perspective; Universitat Politècnica de València: Valencia, Spain, 2011.

50. Hernandis, B.; Briede, J. An educational application for a product design and engineering systems using integrated conceptual models. Ingeniare Rev. Chil. Ing. 2009, 17, 432-442. [CrossRef]

51. Howard, T.; Culley, S.; Deconinck, E. Describing the creative design process by the integration of engineering design and cognitive psychology literature. Des. Stud. 2008, 29, 160-180. [CrossRef]

52. Poveda, P.; García-Díaz, J.; Cañón, G. Conceptual Model and Route to Implement a Comprehensive Management System QHSE3+, in New Trends in Operations Research and Administrative Sciences. An Approach from Latin American Studies. 2017, pp. 115-164. Available online: https://bonga.unisimon. edu.co/handle/20.500.12442/2601 (accessed on 12 September 2019). (In Spanish).

53. ISO. ISO 9001:2015, Quality Management Systems—Requirements; ISO/IEC: Geneva, Switzerland, 2015.

54. ISO. ISO 45001:2018, Occupational Health and Safety Management Systems-Requirements; ISO/IEC: Geneva, Switzerland, 2018. 
55. ISO. ISO 14001:2015, Environmental Management Systems-Requirements with Guidance for Use; ISO/IEC: Geneva, Switzerland, 2015.

56. ISO. ISO 50001:2018. Energy Management Systems—Requirements with Guidance for Use; ISO/IEC: Geneva, Switzerland, 2018.

57. Ogutu, J.; Ben, M. Closing the gap: between traditional and enterprise risk management systems. Am. Soc. Saf. Eng. 2018, 63, 42-47.

58. ISO. ISO 21500:2012, Guidance on Project Managemente; ISO/IEC: Geneva, Switzerland, 2018.

59. Project Management Institute. A Guide to the Project Management Body of Knowledge; PMBOK Guide; PMI Inc.: Lemoyne, PA, USA, 2017.

60. Golini, R.; Kalchschmidt, M.; Landoni, P. Adoption of project management practices: The impact on international development projects of non-governmental organizations. Int. J. Proj. Manag. 2015, 33, 650-663. [CrossRef]

61. Marcelino, S.; González, L.; Pérez, A. Using project management as a way to sustainability: From a comprehensive review to a framework definition. J. Clean. Prod. 2015, 99, 1-16. [CrossRef]

62. Archer, F.; Ghasemzadeh, F. An integrated framework for project portfolio selection. Int. J. Proj. Manag. 1999, 17, 207-216. [CrossRef]

63. Velásquez, S.; Londoño, J.; López, C.; Vahos, J. A multimedia web platform development for project formulation under the logical framework methodology. Lámpsakos 2017, 18, 12-20. [CrossRef]

64. Sartorius, R. The logical frame work approach to project design and management. AJE 1991, 12, $139-147$.

65. Sánchez, N. The logical framework methodology for planning, monitoring and evaluation of projects. Visión Gerenc. 2018, 2, 332-343. (In Spanish)

66. Crawford, P.; Bryce, P. Project monitoring and evaluation: A method for enhancing the efficiency and effectiveness of aid project implementation. Int. J. Proj. Manag. 2003, 21, 363-373. [CrossRef]

67. Casas, G.; Scorza, F. Sustainable Planning: A Methodological Toolkit. In Proceedings of the 16th International Conference on Computational Science and Its Applications-ICCSA 2016, Beijing, China, 4-7 July 2016.

68. Rosato, M. Go Small for Project Success. PMWJ 2018, 7, 1-10.

69. San Cristóbal, J.; Carral, L.; Díaz, E.; Fraguela, J.; Iglesias, G. Complexity and project management: A general overview. Complexity 2018, 2018, 1-10. [CrossRef]

70. Motoa, G. Measurement of project success, a review of the literature. Ingenium 2015, 9, 11-25.

71. Ramasesh, R.; Browning, T. A conceptual framework for tackling knowable unknown unknowns in project management. J. Oper. Manag. 2014, 32, 190-204. [CrossRef]

72. Pollack, J. The changing paradigms of project management. Int. J. Proj. Manag. 2007, 25, 266-274. [CrossRef]

73. Fernández, V.; Vigil, J. Clusters and territorial development. Theoretical review and methodological challenges for Latin America. Econ. Soc. Y Territ. 2007, 6, 859-912.

74. Lamers, M. Do you manage a project, or what? A reply to "Do you manage work, deliverables or resources". Int. J. Proj. Manag. 2002, 20, 325-329. [CrossRef]

75. Kaplan, R.; Norton, D. Translating Strategy into Action. In The Balance Scorecard; Harvard Business School Press: Boston, MA, USA, 1996; 322p, ISBN 0-87584-651-3.

76. Suviri, J. Conceptualization and comparison of different models of corporate reputation assessment. Rev. Responsab. Soc. Empresa 2010, 4, 179-190. (In Spanish)

77. Torabi, S.; Giahia, R.; Sahebjamniab, N. An enhanced risk assessment framework for business continuity management systems. Saf. Sci. 2016, 89, 201-218. [CrossRef]

78. Gil, A.; Varela, G.; González, A. Practical Guide for the Implementation of the Standard UNE 166002: 2006 in Companies of the Residential Building Sector; Tekniker Foundation: Bilbao, Spain, 2008. (In Spanish)

79. Baccarini, D. The Logical Framework Method for Defining Project Success. Proj. Manag. J. 1999, 30, $25-32$. [CrossRef]

80. Jin, K.; Sung, C. Electric energy consumption prediction by deep learning with state explainable autoencoder. Energies 2019, 12, 739.

81. Girbau, F.; Díaz, F.; Sumper, A. Optimization of the operation of smart rural grids through a novel energy management system. Energies 2018, 11, 1-28.

82. Nahida, M.; Mahmud, A.; Maung, A. A Hierarchical transactive energy management system for energy sharing in residential microgrids. Energies 2017, 10, 2098. 
83. Casals, M.; Gangolells, M.; Forcada, N.; Macarulla, M.; Giretti, A.; Vaccarini, M. SEAM4US: An intelligent energy management system for underground stations. Appl. Energy 2016, 166, 150-164. [CrossRef]

84. Matrawy, K.; Mahrous, A.; Youssef, M. Energy management and parametric optimization of an integrated PV solar house. Energy Convers. Manag. 2015, 96, 373-383. [CrossRef]

85. Kyriakarakos, G.; Dounis, A.I.; Arvanitis, K.G.; Papadakis, G. A Fuzzy logic energy management system for polygeneration microgrids. Renew. Energy 2012, 41, 315-327. [CrossRef]

86. Johansson, M.T.; Thollander, P. A review of barriers to and driving forces for improved energy efficiency in Swedish industry-Recommendations for successful in-house energy management. Renew. Sustain. Energy Rev. 2018, 82, 618-628. [CrossRef]

87. Jovanović, B.; Filipović, J. ISO 50001 standard-based energy management maturity model-proposal and validation in industry. J. Clean. Prod. 2016, 112, 2744-2755. [CrossRef]

88. Majernik, M.; Bosak, M.; Stofova, L.; Szaryszova, P. Innovative model of integrated energy management in companies. Qual. Innov. Prosper. 2015, 19, 22-32. [CrossRef]

89. Vermeeren, R.; Mulder, B.; Meta, B.; Reijnders, M. Implementation of ISO 50001 in Industry in The Netherlands. ECEE Industry Summer Study. 2012, pp. 679-688. Available online: www.eceee.org (accessed on 2 March 2019).

90. Bunse, K.; Vodicka, M.; Schönsleben, P.; Brülhart, M.; Ernst, F.O. Integrating energy efficiency performance in production management-gap analysis between industrial needs and scientific literatura. J. Clean. Prod. 2011, 19, 667-679. [CrossRef]

91. De Groot, H.; Verhoef, E.; Nijkamp, P. Energy savings by firms: Decision- making, barriers and policies. Energy Econ. 2001, 23, 717-740. [CrossRef]

92. Cooremans, C. Investment in energy efficiency: Do the characteristics of investments matter? Energy Effic. 2012, 5, 497-518. [CrossRef]

93. Schoenberger, H.; Canfora, P.; Dri, M.; Galvez-Martos, J.L.; Styles, D.; Antonopoulos, I. Development of the EMAS Sectoral Reference Documents on Best Environmental Management Practice. Learning from Frontrunners Promoting Best Practice. Publications Office of the European Union. 2014. Available online: https://publications.jrc.ec.europa.eu/repository/bitstream/JRC84966/lfna26291enn.pdf (accessed on 25 September 2019).

(C) 2019 by the authors. Licensee MDPI, Basel, Switzerland. This article is an open access article distributed under the terms and conditions of the Creative Commons Attribution (CC BY) license (http://creativecommons.org/licenses/by/4.0/). 